\title{
PRELACIÓN, ISONOMÍA Y AGRUPAMIENTO DE CRÉDITOS EN LA EJECUCIÓN CIVIL
}

\author{
["Priority, Isonomy and Credit Grouping in Civil Execution"]
}

\author{
Álvaro Pérez Ragone* \\ Pontificia Universidad Católica de Valparaíso
}

\begin{abstract}
RESUMEN
¿Pars conditio creditoris" o "prior in tempore potior in iure" como principios y marco para la concurrencia de acreedores en la ejecución singular? Este artículo no se centra en un ordenamiento jurídico positivo en particular, sino más bien trata de comparar el desempeño de diferentes sistemas (y criterios) de distribución en la ejecución civil con concurrencia de acreedores. La referencia tanto a la Historia como a modelos procesales civiles comparados debe contribuir a identificar los argumentos en pro y contra de las distintas visiones. La explicación de las alternativas aisladas de isonomía (o contribución), prioridad y agrupamiento permiten plantear los principios de trasfondo y los
\end{abstract}

\begin{abstract}
¿Conditio creditoris Pars" or "prior in tempore potior in iure" as principles and framework for concurrent execution creditors in the singular? This article does not focus on a particular positive law, but rather aims to compare the performance of different systems (and criteria) distribution with concurrent civil enforcement of creditors. The reference to both the history of civil procedure as compared models should help to identify the arguments for and against different views. The alternative explanation equality isolated (or contribution), priority and allow grouping founded on the principles of background and emerging models with inner exceptions. Therefore, rather than
\end{abstract}

* Profesor de Derecho procesal civil de la Pontificia Universidad Católica de Valparaíso. Dirección postal: Pontificia Universidad Católica de Valparaíso, Facultad de Derecho, Avda. Brasil 2950, Valparaíso, Chile. Correo electrónico: alvaro.perez@ucv. cl Este trabajo forma parte de dos proyectos de investigación en curso: Fondecyt $\mathrm{N}^{\circ}$ 1111021: "Principios de la tutela ejecutiva del crédito", como investigador principal; y Fondecyt No 1100530: "Hacia una nueva justicia concursal"; en ambos el autor actúa como co-investigador. 
modelos emergentes con sus excepciones internas. Por lo tanto, más que propugnar por un principio en particular, se trata de justificar las bondades de uno donde prime la prelación combinada con los otros según los derechos en pugna y el estado o no de insolvencia del deudor común. Parece ser que el reconocimiento de la libertad y responsabilidad (en definitiva el juego de la autonomía de la voluntad) para exigir ejecutivamente la tutela de un crédito no se corresponde con la igualdad artificial de trato y contribución-asunción de pérdidas y beneficios conjuntamente con otros acreedores. Las razones de justicia para optar por un modelo frente a otro son el centro de atención en esta investigación.

Palabras clave

Prelación - Concurso de acreedores - Insolvencia. advocating a particular principle, it is justified where the benefits of a prime priority as combined with other competing rights and the state or common debtor's insolvency.It seems that the recognition of freedom and responsibility (ultimately the game of autonomy) to require executive-protection of a credit does not correspond to equal treatment and artificial-contribution of losses and benefits together with other creditors. The reasons for Justice to choose a model over another are the focus of attention in this research.

KeYwords

Priority- Creditors concurrence- Insolvency (personal-corporate).

[RECIBIDo el 2 de noviembre y ACEPTADo el 12 de diciembre de 2011].

\section{INTRODUCCIÓN}

Un ámbito interesante para analizar los costos de transacción, con enorme asimetría informacional y sobre todo competitividad o concurrencia imperfecta bien marcadas son la ejecución singular y universal. Por un lado, i) los acreedores que concurren contra un ejecutado común pueden no conocer totalmente la situación patrimonial del deudor, incluso la existencia misma del concurso (pluralidad) mismo. Pero incluso ii) suponiendo un sistema perfecto y simétrico de información la competencia por verse satisfechos en sus respectivos créditos marcaría una diferencia relevante. Así si uno tiene derecho a 100 , otro a 50 y un tercero a 20 , frente a la posibilidad real del deudor común para pagar un total de 150, cada uno de los acreedores es previsible que tengan interés en ser pagados antes que los otros y en su totalidad. Pero como veremos la imperfección de la competencia podría llevar a que incluso puedan solo ser satisfechos solo dos de aquellos. ¿Qué reglas serían las óptimas para organizar y ordenar con cierta previsibilidad esta competencia para mitigar su imperfección? Pues podría por ejemplo esta- 
blecerse que todos los acreedores son iguales y por ende al menos legalmente tendríamos una ficción de competencia perfecta donde cualquiera de nuestros acreedores en cualquier momento y condiciones podría ver satisfecho al menos un porcentaje de su crédito según su cantidad comparativa con la de los otros. El prorrateo en nuestro caso debiera otorgar mayor porcentaje al acreedor de 100 que al de 20. Podríamos incluso operar con la hipótesis de iii) una competencia perfecta, pero entonces habría que indagar sobre los costos que generaría. Ya con una propuesta como la ofrecida en ii) hay pérdida para cada uno de los acreedores ya que ninguno recibiría el 100\% de lo que reclama. Pero incluso suponiendo que este costo resultara irrelevante para aquellos, tendríamos un deudor ejecutado que quedaría sin posibilidad alguna de pago futuro ya que solo disponía de 150 y volver a esa situación patrimonial podría llevar su tiempo, incluso descartando que hasta entonces surjan nuevos acreedores ${ }^{1}$.

En nuestro ejemplo, pero del mundo real debiéramos además considerar a lo imperfecto del mercado, la conducta racionalmente estratégica de los sujetos interesados intervinientes encontrándonos con un dilema del prisionero o un verdadero laberinto (de acreedores) como calificaba ya a esta situación uno de los primeros estudiosos del fenómeno en el siglo XVIII ${ }^{2}$ ) difícil de ser abordado y resuelto a costo cero. Sí se podría al menos señalar márgenes de conductas cooperativas o competitivas que generen costos cero, negativo o positivo y así preveerse cierta maximización de beneficios con disminución de costos ${ }^{3}$. En todo caso no pretendo más que exponer

${ }^{1}$ Para un detalle explicativo y descriptivo sobre la imperfección del mercado en tanto asimetría de información, competencia imperfecta y los costos de transacción, puede verse: Cole, Daniel - Grossman, Peter, Principles of Law \& Economics (2a edición, New York, Wolster Kluwer, 2011), pp. 10-25; Shavell, Steven, Foundation of Economic Analysis of Law (Cambridge, Harvard U. P., 2004), pp. 1-5.

${ }^{2}$ El término es tomado de SAlgado de Somoza, Francisco, Labyrinthus creditorum concurrentium ad litem per debitorem communen inter ilios causata (Fratrum de Tournes, 1757), II, esp. cap. $1^{\circ}$, pp. 306-312 (digitalizado por la biblioteca de Catalunya) quien considero arribó a un primer intento sistematizador de procedimientos trabajando con pluralidad de acreedores y deudor insolvente sentando las bases del Derecho de la insolvencia y su procedimiento. Para un estudio profundizado de los alcances contemporáneos de la obra de Salgado puede verse: Forster, Wolfgang, Konkurs als Véase: fahren: Francisco Salgado de Somoza in der Geschichte des Insolvenzrechts (Köln - Weimar, Böhlau 2009), pp. 295 ss.

${ }^{3}$ Un estudio introductorio al análisis que propongo puede verse en: COLE, Daniel - Grossman, Peter, Institutions Matter! Why the Herder Problem Is not a Prisioner's Dilemma, en Theory \& Decision, 69 (2010) 2, pp. 219-225; véase en especial para lo vinculado a la conducta y acciones estratégicas colectivas: BAIRD, Douglas - GERTNER, Robert - Picker, Randal, Game Theory and the Law (Massachuset, Harvard U. Press, 1998), pp. 191-217. 
los modelos que actualmente existen en torno a la ejecución singular con concurso de acreedores y la eventualidad de la insolvencia.

Tanto en el derecho público como privado se pueden encontrar los más variados criterios y procedimientos para racionalizar y distribuir recursos que son escasos ${ }^{4}$. Lo equitativo y justo del resultado en la distribución depende, aunque no exclusivamente del procedimiento que se escoja. Sin embargo entre tantas alternativas contando con elección racional y juego estratégico como el que será nuestro marco los incentivos predispuestos permiten cierta previsibilidad de un procedimiento como resultado "fair" o "unfair"s. Uno de esos criterios racionales es el temporal. Así en materia de previsión y seguridad social la determinación de los años para tener derecho a pensión es de enorme relevancia. También los sistema de subvenciones en sus diversas formas y por diversas causas suelen fijar su limitación en un momento determinado, el primero que reúna las condiciones para la obtención de un beneficio debiera ser tratado de forma diferente de aquel que reuniendo las condiciones postula fuera de plazo. Los distintos sistemas de "atención al público” o de ingreso de peticiones a la administración pública, al poder legislativo y al mismo poder judicial acuden al "cargo" o momento de ingreso para generar orden de distribución. O simplemente en el área de patentes e invento comercial, tecnológico o industrial ${ }^{6}$.

Este orden de asignación en el tiempo puede encontrarse ya en el derecho romano y medieval. En el primero basta recordar los rangos de prelación de derechos prendarios concurrentes el tiempo ${ }^{7}$. En el segundo ya eran conocidas en el derecho público las reglas para el acceso a cargos públicos como funcionarios del monarca o emperador de acuerdo al momento de postulación con los cupos disponibles ${ }^{8}$.

${ }^{4}$ White, Michell, Bankruptcy Law, en Polinsky, Mitchell - Shavell, Steven (editores), Handbook on Law and Economics (Amsterdam, 2007), cap. 14 , pp. 1014 (1057-1058, 1064-1068)

${ }^{5}$ No pretendo desarrollar lo que entiendo por "lo justo"; creo que para este trabajo basta con identificarlo como las condiciones de trato equitativo a las partes en sus intereses y dignidad, al respecto véase la base de la que partimos como mínima: Bone, Robert, Procedure, Participation and Rights, en Boston Boston University Law Review, 90 (2010), p. 1011 (1027-1028).

${ }^{6}$ Abrams - Wagner, Priority Rules An Empirical Exploration of First-to-Invent Véase: sus First-to-File, en Public Law and Legal Theory (University of Pennsylvania Law School, Research Paper N 11-37, Draft 9.6.2011) [visible en> http://ssrn.com/ abstract $=1921488$, visitado el 20 de octubre de 2011]

${ }^{7}$ V. Kasser, Max, Das Römisches Privatrecht (München, Beck, 1971), I, pp. $466-$ 468.

${ }^{8}$ CoING, Helmut, Europäisches Rechtsgeschichte (München, Beck, 1985), I, pp. $325-330$. 
Es en el derecho germano donde surge la expresión "come primero el que llega primero", la que ha sido objeto de estudios y consecuente aplicación legislativa, por ejemplo en el área que será objeto de tratamiento: la ejecución y al embargo que otorgan al acreedor una prioridad o prelación en relación a aquellos que insten la ejecución posteriormente en el tiempo. En lo que a este trabajo concierne, no pueden dejarse de al menos mencionar los alcances de este principio en diversas áreas del derecho privado patrimonial y extrapatrimonial ${ }^{10}$. No en vano el problema de la concurrencia de derechos puede ser muchas veces resuelto en base a la aplicación del principio de prelación. Su manifestación a través del clásico brocado latino "prior in tempore potior in iure" tuvo una recepción y trato legislativo mucho más fuerte en los sistemas germanos y anglosajones que en los de tradición románica ${ }^{11}$.

También es cierto que la sola prelación por un mero criterio temporal podría conllevar a ciertas injusticias, de allí que se contemplan excepciones al principio para morijerar consecuencias no deseables en determinadas circunstancias. En la insolvencia con ejecución universal (quiebra, ejecución concursal o universal), rige justamente otro principio que impone la igualdad de trato a los acreedores: "par conditio creditorum" ${ }^{2}$. La razón de la exclusión del criterio de prelación temporal es justamente la imposibilidad del patrimonio ejecutado para satisfacer las obligaciones asumidas y con ello no afectarse desproporcionadamente intereses tanto de los acreedores concurrentes como del ejecutado. Principio que por cierto no ha tenido mayor controversia en su

${ }^{9}$ W ACKe, Andreas, Wer zuerst kommt, mabl zuerst, en Juristen Ausbildung (1981), pp. 94 ss. La regla era aplicada desde el Medioevo para el empleo de los molinos que funcionaban con impulso hídrico o eólico. El "molinero" se cobraba en dinero o especies la prestación de la molienda respetándose estrictamente el orden de llegada.

${ }^{10}$ Un excelente aporte para el estudio del principio de prelación dentro del derecho como introducción a su tratamiento en especial en la ejecución civil, fue desarrollado por Fragistas, Charalambos, Das Präventionsprinzip in der Zwangsvollstreckung (Mannheim, 1931), pp. 5 -20 esp.; cfr. por cierto con Kerameus, Konstantinos, Enforcement in the International Context, en Recueil des Cours, 264 (1997), pp. 306 ss.; SIEBERT, Peter, Das Prioritätsprinzip in der Einzelzwangsvollstreckung (Diss. Göttingen 1988), pp. 172 ss.

${ }^{11}$ Becker, Colin, First in Time, First in Right (Berlin, Duncker \& Humblot, 2000), pp. 27- 30; cfr. Neuner, Jörg, Der Prioritätsgrundsatz im Privatsrecht, en Archiv für die Civilistische Praxis, 203 (2003), p. 46. Sobre la formulación paralela al principio de prelación desde la Edad Media hasta la Moderna y su recepción en los países europeos, véase: Levinthal, Louis Edward, The Early History of Bankruptcy Law (Pennsylvania, 1918), pp. 19-25; Vollmershausen, Christiane, Vom Konkursprozess zum Marktbereinigungsverfahren (Münster, LIT, 2007), pp. 304-307

${ }^{12}$ Véase en general: STÜRNER, Rolf, Prinzipien der Einzelvollstreckung, en Zeitschrift für Zivilprozess, 99 (1986), pp. 291-332; Fuchs-Wissemann, Hanns, Priorität und Recht, en Deutsche Richter Zeitung (1982), pp. 373 ss. 
recepción en el derecho concursal o de la insolvencia nacional, transnacional, comunitaria y comparada ${ }^{13}$. En efecto frente a un patrimonio insolvente que no alcanza a satisfacer todos los créditos, corresponderá una división o prorrateo de lo poco que, y en igualdad de trato, corresponde a todos los acreedores intervinientes en la medida de su crédito ${ }^{14}$.

También el criterio temporal puede asumir relevancia por la naturaleza propia del derecho en su carácter de absoluto y oponible. Así por ejemplo en las relaciones reales de garantía. Un bien del patrimonio del ejecutado puede haber sido prendado o hipotecado para garantizar una obligación totalmente diferente subjetiva, causal y objetivamente de aquella que motiva esa ejecución individual y en la cual se traba un embargo. Un mismo deudor frente a acreedores concurrentes, uno que instó y obtuvo primero en el tiempo el embargo en la ejecución, el otro que podría obtener igual resultado con posterioridad. No obstante éste tiene una ventaja dada por el derecho real de garantía sobre el bien que por su naturaleza debe desplazar al crédito en base al cual se ejecuta y sustenta el embargo. Así corresponde un trato justificadamente desigual $-y$ preferente- a los acreedores por un derecho real de garantía. Igual suerte corren aquellos derechos que indirectamente tienen efectos de prelación adjudicados por la publicidad registral, sea constitutiva o meramente declarativa. Pero agreguemos otro ejemplo a éste. Un bien inmueble cuya adquisición ya se realizó por la inscripción en el respectivo registro ya no se encuentra más en el patrimonio del tradens por haberse satisfecho el requisito registral "constitutivo" de la transferencia. De la misma forma si ese inmueble en el patrimonio del nuevo dominus fuere embargado, la restricción de disposición se inscribirá en el registro correspondiente y logrará así una finalidad declarativa, de modo tal que nadie podría alegar que en su buena fe desconocía ese gravamen. Nuestro dominus con el bien embargado y registralmente perfeccionado, no podría a su vez enajenar ese bien por la propia dinámica y efecto negativo de la declaración contenida en los registros. Al menos en el contraste ejecución singular-universal (insolvencia) los supuestos de excepciones a los principios

${ }^{13}$ Cfr. HEss, Burkhard, Europäische Zwangsvollstreckungsrecht: Herausforderung und rechtpolitische Perspektiven, en Die Deutsche Gerichtsvollzieher Zeitung (2010), p. 21; véase: Pluta, Maximilian, Insolvenzaufrechnung und der Grundsatz der "par conditio creditorum" (Bielefeld, Gieseking, 2009), pp. 119-129.

${ }^{14}$ Véase: SCHLOSsER, Peter, Volksstreckungsrechtliches Prioritätsprinzip und verfassungsrechtliche Gleiheitssatz, en Zeitschrift für Zivilprozessrecht, 97 (1984), pp. 121 ss.; contra la posición de Schlosser: WelBers, Hartwig: Vollstreckungsrechtliches Prioritätsprinzip und verfassungsrechtlicher Gleichheitssatz (Diss., Bonn 1991), pp. 10-25; para un examen de la igualdad de trato, la insolvencia y el Derecho Constitucional, puede verse: LePA, Brita, Insolvenzordnung und Verfassungsrecht (Berlin, Ducker \& Humblodt, 2002), pp. 22-31. 
tienen cierta justificación que varían según el sistema jurídico. No obstante es curioso ver ciertos acercamientos y necesidades de morigerar la aplicación tajante del principio prior in tempore versus el principio par conditio ${ }^{15}$.

Traspolando estos planteos introductorios a la ejecución civil y distribución entre los acreedores concurrentes es que trataremos los diferentes modelos existentes. Una presentación de ellos que será por cierto solo a los fines expositivos ya que la realidad comparada demuestra que se arriban a modelos ciertamente mixtos que logran cierta armonía en la información, competencia y costos de transacción ${ }^{16}$. Debo hacer sí tres aclaraciones previas: $i$ ) este artículo no pretende concentrarse en ningún sistema positivo en especial, mas bien intenta comparar el funcionamiento de los distintos sistemas (y criterios) de distribución y los principios que los rigen; el recurso a detalles históricos y de Derecho comparado debería servir a ello; ii) tampoco se fijan propuestas de lege ferenda en referencia en concreto a la ejecución civil en Chile aunque justamente este modelo resulta muy atractivo para su análisis y crítica, al menos de lege lata. El lector no encontrará ninguna cita, referencia bibliográfica o vinculación con el derecho positivo chileno justamente para que pueda identificar realidades a partir del derecho comparado, quizás muchos juicios puedan emitirse también para la casi inexistente y poco coherente regulación de la concurrencia de acreedores e insolvencia en el país; iii) sí se procura examinar los componentes de equidad y justicia sobre los que cada sistema intenta legitimarse. Si de este último, complejo pero humilde propósito, algunas luces se puedan aportar para la mejora de un derecho positivo en particular se habrá excedido con creces lo planificado.

Las afirmaciones antes enunciadas de supuestos en los cuales la prelación temporal se admite y otros en los que directamente corresponde sea descartada, deben sin embargo ser justificadas con mayor detalle que la simple remisión a una decisión de orden legislativa. Es así que intentaré fundar necesidad de la prelación en la ejecución civil singular analizando las diversas soluciones que se han dado en el derecho comparado para resolver un problema muchas

${ }^{15}$ Schpani, Sandro, "Principia Iuris. Principium potissima pars". Principios generales del derecho (Apuntes para una investigación), en Roma e America. Diritto Romano Comune, 3 (1997), pp. 3 ss.; para un estudio histórico y comparado detallado véase: KERAMEus, Konstatinos, Enforcement Proceedings, International Encyclopedia of Comparative Law, XVI: Civil Procedure, en CAPPELETTI, Mauro (editor) (Tübingen, 2002), cap. $10^{\circ}$, pp. 84-87.

${ }^{16}$ Kerameus, Konstatinos, Actual Problem of Enforcement Law in the European Union, en Homenaje a Peter Schlosser zum 70. Geburstag. Grenzüberschreitungen (Tübingen, Mohr-Siebeck, 2005), pp. 355 ss. 
veces ignorado, cual es el de la concurrencia de acreedores en la ejecución singular con el fantasma actual o potencial de la insolvencia ${ }^{17}$.

Presento la importancia del principio de prioridad o prelación como un principio del derecho examinado en el derecho privado tomando solo como ejemplos algunas áreas como introducción para contextualizarlo especialmente dentro de la ejecución civil singular (II) . Los modelos y contornos paralelos además del de prioridad son detallados e interrelacionados (III) como una introducción al examen analítico posterior de cada uno comenzando por el isonómico (IV), siguiendo por el de prelación (V), para concluir con el de agrupamiento o clases de acreedores (VI). Ahora bien, planteados los sistemas y sus relaciones con la ejecución (singular y universal) se propone un tratamiento de la ejecución civil frente al fenómeno de la concurrencia y el evento de la insolvencia para proponer una base conjunta similar, proponiendo diferencias claras en sus fines y principios (VII). Se propone finalmente la justificación del principio de prelación para la ejecución civil singular, como el de igualdad de trato para la universal, no como antípodas, sino como complementarios uno de otro sin olvidar al de agrupamiento. Ello no solo se verifica en realidades positivas ya existentes, sino además en pretendidas igualdades donde de hecho hay prelación y viceversa (VIII). En la conlusión se resumen los principales planteos uniendo el diagnóstico (quizás también las propuestas de mejora) a una visión integral para la ingeniería de regulación del fenómeno de la concurrencia de acreedores y la insolvencia (IX).

\section{LA PRELACIÓN Y SU MANIFESTACIÓN EN EL DERECHO PRIVADO}

Una clara manifestación sustantiva en el derecho privado de la prelación en el tiempo lo constituye la aplicación de la máxima: "nemo plus iuris ad alium transferre potest, quam ipse haberet" ("nadie puede transferir a otro más derecho del que él mismo tiene” ${ }^{18}$. Así nadie puede transferir, nadie puede adquirir un mejor derecho que el que le es transferido y consecuentemente

${ }^{17}$ FISCHER, Nikolaj, Vollstreckungszugriff als Grundrechtseingriff(Tübingen 2006), p. 5; STAmm, Jürgen, Die Prinzipien und Grundstrukturen des Zwangsvollstreckungsrechts (Tübingen 2007), pp. 16 ss.; BAUR, Fritz, Los principios de prioridad e igualdad en la jurisdicción voluntaria, en Boletín Mexicano de Derecho Comparado, 22-23 (1975), p. 88.

${ }^{18}$ La máxima fue recibida en el Digesto (D. 50,17,54). Ella ha sido aplicada incluso en la Filosofía y Teoría constitucionales; véase al respecto: Koenne, Phil, The Cult of Legislation (New York, Publishing Packagers Corp., 1991), pp. 5-29, refiriéndose a la aplicación del principio en la temprana república romana, dice: "no one can transfer to another more authority than he himself has" ("Nemo plus juris ad alium transferre potest quam ipse haberet")" para aplicarlo a la soberanía del pueblo y los límites de la autoridad (el Estado) como poder derivado. 
un derecho transferido-adquirido no puede ser simultáneamente transferido y adquirido por un tercero. Quien dispone de un bien y quien lo adquiere no podrían volver a reeditar el acto pasado. Ya se dispuso sobre un bien y salvo la celebración de otros actos jurídicos previos es un acto que de verificarse nuevamente nunca sería ex nibilo ${ }^{19}$. Esta regla asume una efectividad mayor cuando se le suma la publicidad registral, la que asegura al adquirente potencial y futuro que el titular que ha de transferir es el que obra en el registro. Así, la publicidad registral logra por un lado poner a disposición y conocimiento que existe ese derecho y que aún no se ha dispuesto sobre él enajenándolo o gravándolo en beneficio de otro. Además, implica para el adquirente que inscribe, que cualquier afectación de ese derecho realizada por el anterior titular registral no le sería oponible ${ }^{20}$.

Muchas son las áreas en las cuales la prelación o prioridad se manifiesta en el derecho privado y que llevan a pensar en la necesidad de una coherente recepción dentro de la tutela procesal correspectiva. Por ejemplo, en el derecho privado patrimonial contractual, la autonomía de la voluntad puede desempeñar un rol importante para determinar los derechos de las partes en relación al momento en el cual sean ejercidos. El juego combinado de las modalidades de los actos jurídicos, sea condición o plazo, pueden establecer en base al libre albedrío de las partes contractuales diferentes criterios de prelación. En el caso del pacto de retroventa puede funcionar como una prelación acordada por las propias partes para que sea el primer vendedor quién tenga derecho a poder ser el primer comprador (en puridad segundo comprador en el tiempo, ya que el primero lo fue quien ahora es el vendedor) frente a otros concurrentes. Similar funcionamiento tiene en la promesa o declaración unilateral de recompensa en relación a posibles futuros y concurrentes beneficiarios.

En el campo de los derechos reales y delimitándonos al derecho de dominio muchos de los modos de adquisición se fundamentan en la prelación temporal. Así, la adquisición de dominio de un bien inmueble por tradición -con registro e inscripción constitutiva- o por prescripción adquisitiva reuniéndose sus requisitos. En ambos casos el que adquiere excluye en el tiempo a otros posibles adquirentes que invoquen el mismo derecho ${ }^{21}$. También se

${ }^{19}$ También este principio es recibido en la Siete Partidas: Part. VII, título $34^{\circ}$ (De las reglas del Derecho), regla $12^{\mathrm{a}}$ "E aun dixeron que ningun ome non puede dar más derecho a otro en alguna cosa, de aquello que le pertenesce en ella".

${ }^{20}$ Cfr. Lasarte, Carlos - López Peláez, Patricia - Yáñez Viver, Fátima, La reforma de la prelación de créditos (Madrid, Cuadernos de Derecho Registral, 2007), pp. 34-37, 118-121.

${ }^{21}$ STADLER, Astrid, Gestaltungsfreiheit und Verkehrsschutz durch Abstraktion (Tübingen, Siebeck, 1996), pp. 249-257, 600-615. 
puede constata el rol de la prelación en los derechos reales de garantía, que por sí mismos priman sobre las garantías personales. El titular de un derecho de crédito hipotecario goza necesariamente de prelación frente a otro que titularice un crédito sin aquella garantía y no por el tipo de crédito, sino por el derecho accesorio al crédito existente en un caso, inexistente en el otro. La prelación no la otorga la relación obligacional principal, sino la accesoria de garantía que es justamente real. Podría muy bien haber sido de naturaleza personal (como es el caso de la fianza) pero incluso en este supuesto debe someterse a la prelación del derecho real de garantía ${ }^{22}$.

Tampoco podría ignorarse la existencia de criterios de prelación en áreas como el derecho sucesorio donde la propia ley los establece en combinación o independientes del tiempo, así por ejemplo la antigua regulación del derecho del hijo primogénito con derechos preferentes en relación a los posteriores. Vale lo suyo también en un ámbito estrictamente no patrimonial como la donación de órganos donde los criterios y bancos de urgencia -de ablación o de urgidos- son establecidos por criterios combinados de tiempo y necesidad ${ }^{23}$.

\section{LOS DISTINTOS MODELOS Y SUS PRINCIPIOS DE TRASFONDO}

Todos los supuestos antes mencionados de aplicación directa, simple o combinada del reconocimiento a la prelación en el derecho privado debieran coherentemente manifestarse en el ámbito procesal de la ejecución. No es extraño al proceso el empleo de prioridades temporales. Así en materia de competencia cuando determinados conflictos se resuelven legislativamente asignando y reconociendo al tribunal que previno o que conoció primero en el tiempo sobre dicho proceso. O el caso de la litispendencia y en la acumulación de autos son solo algunos ejemplos. Pero centrados ya en la ejecución, la vigencia de otro principio debe primar con el reconocimiento de la igualdad de trato a los distintos acreedores. El supuesto de la insolvencia así lo impone para lograr un mínimo de satisfacción de los créditos, con el costo de pérdida parcial o resignada. La lógica de satisfacción parcial parece ser la salida frente a un patrimonio insolvente en relación a los créditos verificados. Razonablemente, de aplicarse la prelación temporal podría implicar no sólo la satisfacción incompleta del primero de los acreedores en el tiempo, sino y hasta la insatisfacción total de uno o varios de los acreedores posteriores. Todos en común verían burlados o insatisfechos sus intereses por la insuficiencia de

${ }^{22}$ Cfr. López Peláez, Patricia, Los créditos preferentes en el Derecho español (Madrid, Trivium, 2001), pp. 14-20.

${ }^{23}$ Neuner, cit. (n. 11), pp. 48 ss. 
un patrimonio del deudor común contra el cual ejercen sus derechos, que solo satisfizo al primer acreedor que instó la ejecución universal ${ }^{24}$.

Esta regla de equidad y funcionamiento del derecho sustantivo no está aislada de la prelación temporal y no resulta difícil trasladarla a la ejecución singular con concurrencia de acreedores y pluralidad de embargos sobre el mismo bien (reembargos). Pero justamente el problema de la concurrencia de acreedores combinado con un deudor (civil y por regla asociado a personas naturales) insolvente ha sido regulado en muchos sistemas aislado del fenómeno concursal del insolvente (comerciante y por regla asociado a personas jurídicas) con aplicación de alternativas y modelos inconexos, muchas veces incoherentes que terminan agravando las asimetrías de competencia y distribuyendo los costos injustamente. Podría justificarse la necesidad de regular la insolvencia independientemente de la calidad de comerciante o persona natural del deudor aplicando allí la igualdad de trato de (o contribución) los acreedores. Igualdad que se manifiesta en la comunidad de beneficios y pérdidas, en la coparticipación en la solvencia como en la insolvencia del Derecho común. Es por cierto lo que doctrinalmente suele acentuarse como distintivo del Derecho Concursal ${ }^{25}$. Para claridad terminológica se emplearán la voz "quiebra" en tanto proceso concursal de insolvencia restringido a determinados sujetos en razón de su calidad como sujeto comerciante (mercantilmente relevante), es decir con una extensión mucho más restringida que la voz "concurso" e "insolvencia" 26.

No obstante ello no sería plausible en caso que, no obstante existir concurrencia de acreedores, el deudor se solvente. El dilema surge claro combinando las distintas alternativas ${ }^{27}$. O podría aceptarse ver satisfecho al acreedor que

${ }^{24}$ Cfr. Mokal, Rizwaan Jameel, Priority as Pathology: the pari passu Myth, en Cambridge Law Journal, 60 (2001), pp. 581-590 esp.

${ }^{25}$ En Brasil, a fines del siglo XIX y comienzos del XX, el debate fue entre las alternativas de la prioridad o de la insolvencia, sin consideración a la calidad de comerciante; en la discusión francesa, italiana y alemana fue entre igualdad e insolvencia solo para comerciantes, sobre lo cual, véase: en De CASTro jr., Francisco, Da insolvencia civil no ponto de vista do Direito patrio, da historia e da legislação comparada (São Paulo, Laemmert, 1903), pp. 21-26

${ }^{26}$ Así, siguiendo lo propuesto por Olivencia Ruiz, Manuel, La terminología jurídica de la reforma concursal (Madrid, Iustel, 2006), p. 87; cfr. CORTÉs DOMÍNGUEZ, Valentín, La naturaleza jurídica de la declaración judicial de concurso, en Olivencia, M. - Jiménez de Parga, R. - Fernández-Novoa, C. (directores) Derecho procesal concursal (Barcelona, Marcial Pons, 2008), p. 29.

${ }^{27}$ Es así que el fenómeno de la concurrencia puede tratarse como la regulación coherente y coordinada frente a la pluralidad de acreedores (colectivo), siendo la insolvencia solo un estado eventual; véase al respecto la obra colectiva bajo la dirección de DE Leval, Georges, Seizure and Overindebtedness in the European Union (La Haya 1997), passim, relevante en la matriz de cada uno de los aportes nacionales 
primero hace valer sus derechos, debiendo soportar la eventualidad de la insolvencia los acreedores posteriores (previsión de insolvencia ex ante). $\mathrm{O}$ bien, partir ignorando la eventualidad de la insolvencia (con previsión $e x$ post cuando ese patrimonio ya resulta insuficiente para responder) ya que todos los acreedores concurrentes deben ser tratados en pie de igualdad y por ende debieran todos soportar un riesgo que es futuro e incierto y que afectando a personas naturales corresponde sean tratados dentro de la ejecución singular y en su caso no satisfaciéndose ninguno en la totalidad de su crédito. Frente a dos alternativas extremas el punto medio también ofrece una respuesta a partir de la combinación de aquellas. Prelación para un grupo de acreedores por haber ejercido sus derechos en un determinado espacio de tiempo, frente a otros que lo hicieron con posterioridad: clases o grupos temporales de prelación ${ }^{28}$.

Solo como dato anecdótico debo referir a la discusión en Alemania durante la década de los ochenta en el siglo XX sobre las distintas alternativas de técnica procesal ejecutiva y en definitiva de distribución de bienes o de la universalidad del patrimonio habiendo concurrencia de acreedores. Se requirió la inconstitucionalidad del principio de prelación en el ejecución civil singular. Si bien minoritario tanto la doctrina como un voto disidente en el Tribunal Constitucional consideró que el principio de prelación vulneraba la igualdad establecida por la Constitución en su artículo 3 inciso $1^{029}$.

Permítaseme partir de estas hipótesis sobre coincidencias y divergencias de modelos antes enunciadas: podría darse cabida a la prelación con un reconocimiento al acreedor diligente, temporalmente primero en actuar y ser beneficiado con un embargo; pero ello no es suficiente y debieran también contemplarse criterios legales que solucionen o reduzcan racional y previamente el problema de la concurrencia; finalmente sería recomendable una opción preventiva frente a la insolvencia de un deudor común cuando existan acreedores concurrentes distribuyendo el riesgo entre los que instaron la ejecución con posterioridad. Estas propuestas podrían mejorar la relación

${ }^{28}$ Cfr. TARZIA, Giusseppe, La distributions des derniers dans lexécution forcée en Europe, en Revue Internationale de Droit Comparé, 51 (1999) 2, pp. 331 ss.; cfr. con GaUl, Hans F., Rechtsverwirklichung durch Zwangsvollstreckung, en Zeitschrift für Zivilprozess, 112 (1999), pp. 135 ss.; últimamente similar llamado de atención sobre el tema hace Kawano, Masanori, Civil Enforcement as a Fundamental of Effective Justice-Introductory Remarks on Comparative Study of Civil Enforcement, en STÜRNER, R - Kawano, M. (directores), Comparative Studies on Enforcement and Provisional Meassures (Tübingen, Siebeck, 2011), pp 4 ss.

${ }^{29}$ Puede verse el voto especial de Böhmer, en $B V e r G E .$, 49, p. 220. Para un examen y refutación de los argumentos constitucionales contra la prelación véase: WELBERS, Hartwig, Vollstreckungsrechtliches Prioritätsprinzip und verfassungsrechtlicher Gleichheitssatz (Diss., Bonn 1991), pp. 10-25. 
costo/beneficio y previsibilidad individual y social de los interesados intervinientes acreedores, deudor $\mathrm{y}$ terceros ${ }^{30}$. Ninguna de las propuestas, incluso la que se proponga como la más aceptable pueden examinarse sin relacionar el derecho sustantivo de las obligaciones, la regulación de la insolvencia (civil y mercantil) y la ejecución civil singular ${ }^{31}$.

\section{SiSTEMA ISONÓMICOS DE CONTRIBUCIÓN: IGUALDAD DE TRATO A LOS ACREEDORES}

Un modelo posible es aquel donde el tratamiento de los acreedores es igualitario. Ello no sería sino manifestación de la igualdad de los derechos de crédito frente a la ley y consecuentemente su tratamiento en el proceso, de forma que finalmente los acreedores terminen siendo satisfechos (todos) y de la misma manera ${ }^{32}$. No es menor ver en la fuente francesa la inspiración de los postulados de la Revolución con énfasis en la igualdad que debía traducirse y reflejarse en todo el sistema, también en el trato a los acreedores ${ }^{33}$. En la práctica el sistema de igualdad de trato a los acreedores se convierte en un pequeño procedimiento colectivo de acreedores que concurren en igualdad

${ }^{30}$ Para el costo y gravamen de los consumidores en las relaciones financieras y la imposibilidad de excluirlos del mercado por el costo personal-familiar-económicosocial: Engel, Kathleen - Mccoy, Patricia, The Subprime Virus (Oxford, Oxford U. Press, 2011), pp. 227-236; especial referencia al uso de las prelaciones en las relaciones financieras con personas naturales en insolvencia como excepción al de prioridad temporal véase: el nutrido informe sobre la liquidación de compañías financieras del año 2011 elaborada en los Estados Unidos por el consejo de Gobernadores que integran el Sistema Federal de Reservas (p. 6) [www.federalreserve.gov/boarddocs/rptcongress/ default.htm, visitado el 11 de agosto de 2011].

${ }^{31}$ En general, para la importancia de la coordinación en la concurrencia con insolvencia, puede verse el estudio comparado (si bien en muchos casos desactualizado) de KrIngs, Ernerst, Seizure and Overindebtedness in the European Union, en De Leval, Georges (director), Seizure and Overindebtedness, cit. (n. 27), pp. 41-46; véase igualmente: Pond, K., Creditor Strategy in Individual Insolvency, en Managerial Finance, 28 (2002) 6, pp.46-60; para un estudio actual del impacto y los mecanismos para reencauzar la insolvencia personal véase CuMming Douglas, Measuring the effect of bankruptcy laws on entrepreneurship across countries, Journal of Entrepreneurial Finance, en prensa (2011), [pero ya en: http://ssrn.com/abstract=1970042, visitado última vez 10.11.2011],passim

${ }^{32}$ Introductorio el examen de Donnier, Marc - Donnier, Jean-Baptiste, Voies d'exécution et procedure de distribution (Paris, Litec, 2009), pp. 58, 504 s. Para un examen con matrices sobre el sistema de contribución o de igualdad en la ejecución civil (focalizado en Francia) ThÉry, Phlippe, Seizure and Overindebtedness in the European Union, en DE Leval, G. (director), Seizure and Overindebtedness, cit. (n. 27), pp. 305-315.

${ }^{33} \mathrm{KAHIL}$, Omran, L'égalité entre les créanciers Dans le cadre de la saisie attribution, Tesis doctoral Universidad Lille 2 (Francia, 2011), pp. 4-25 
de condiciones. Claro está que no representa un problema el supuesto del deudor solvente cuyo patrimonio alcanza a satisfacer por completo cada uno de los créditos que se hacen valer en su contra. Tampoco representa mayor complejidad el supuesto de acreedores cuyos derechos tienen una garantía real, es decir tienen asegurado su crédito mediante un derecho real de garantía prenda o hipoteca. Así estos derechos se constituyeron con anterioridad al ejercicio de las acciones correspondientes a los otros acreedores sin derecho real de garantía o, siendo que los derechos sobre los cuales se se ejecuta la garantía excluye a los embargos que puedan efectuarse dentro de un sistema de publicidad registral constitutiva o meramente declarativa ${ }^{34}$. Dentro de este modelo de trato igualitario también se contempla, en el caso de comerciantes o empresarios (empresas), un sistema especial de tratamiento frente a la insolvencia del ejecutado común. Allí es aplicable por la calidad del deudor insolvente el procedimiento concursal de insolvencia o la quiebra, no pensado para personas naturales. Quienes tengan preferencias para ser pagados constituirán una clase común con otros acreedores y desplazarán en el pago a quienes carezcan de aquellas (acreedores valistas o quirografarios) ${ }^{35}$.

De esta forma aquellos acreedores que concurren en una ejecución singular y que no revisten las condiciones subjetivas de comerciante o empresa para solicitar la apertura de un procedimiento concursal, deben soportar dos eventualidades. Por un lado la posibilidad de la existencia de acreedores con ciertos derechos reales de garantía documentados (por ser ésta normalmente la condición o exigencia de solemnidad) o inscritos en los correspondientes registros (por ser el medio de publicidad (inscripción declarativa) o exigencia constitutiva del derecho real de garantía (inscripción constitutiva) $)^{36}$. Por otro lado los acreedores quirografarios deben concurrir

${ }^{34}$ STAdler, cit. (n. 21), pp. 249-259; cfr. con Lasarte - López PeláeZ - YÁÑez Vivero, cit. (n. 20.), pp. 17-43. Así se habla de prioridad registral y trato igualitario declarativo o de conocimiento presunto que impide alegar la buena fe.

${ }^{35}$ Sobre el sistema de contribución o de igualdad de trato en Bélgica, véase: DE LEVAL, George - PARTSCH, Philippe-Emmanuel, Seizure and Overindebtedness in the European Union en De Leval, D. (director), Seizure and Overindebtedness, cit. (n. 27), pp. 183 ss. Como sostienen los autores el sistema similar al del resto de los países bajos solo reconoce aquellos "privilegios legítimos" establecidos por decisión del legislador, sin contemplación al orden temporal aunque dependiendo del tipo de bien y la medida ejecutiva puede otorgar derechos al acreedor para la venta del bien y véase: pagado su crédito aun cuando luego aparezcan otros acreedores.

${ }^{36}$ Frente a estos acreedores aquellos que solamente ejercieron la medida conservativa del embargo no gozan de ningún trato sino simplemente se les otorga la posibilidad de hacer valer sus derechos a través de un incidente especial en la ejecución civil singular (es decir, con un costo eventual de litigiosidad). Cfr. la crítica al sistema MEIER Isaak PERrier Camille, Sanierung und Entschuldung von Privatpersonen nach französischem 
en la ejecución singular asumiendo la insolvencia del ejecutado, para lo cual mediante un incidente especial dentro de la ejecución podrán impedir que se haga pago del todo a cualquiera de estos y que por el contrario en base al trato igualitario de sus créditos, se satisfagan los mismos por un patrimonio insuficiente acudiendo al prorrateo. De esta forma cada uno de los acreedores es satisfecho en su interés por porcentaje de acuerdo a la totalidad del crédito invocado. Es en los hechos un procedimiento (concursal) de insolvencia dentro de la ejecución singular que no termina satisfaciendo los derechos de los acreedores en su integridad.

La fuerza del principio de trato igualitario puede verse en los sistemas ejecutivos contemporáneos sobre la base del Code Civil francés de 1804 (artículo 2093 actualmente artículo 2285) y el Code de la Procédure Civil de 1806 (artículo 656) ${ }^{37}$. Este sistema rigió incluso en los países germanos hasta antes de la codificación procesal civil y de quiebras de $1879^{38}$.

El legislador francés del siglo XX ha tenido que ceder a la igualdad de trato absoluta de los acreedores, como así también prestar atención al fenómeno de la insolvencia de las personas naturales aunque sin dar mucho espacio al principio de prioridad. Me centro en tres supuestos ejemplificatorios para demostrar cómo la isonomía original de la ejecución singular y el aislamiento de toda relación con la insolvencia terminan flexibilizándose. Es bastante interesante desde el punto de vista de la técnica legislativa, como se terminaron contemplando en el siglo XX supuestos de insolvencia de deudores que no revisten la calidad de comerciantes. Ello no ha sido incluido en el código procesal civil francés, ni en la ley de concursos o de insolvencia, sino como un acápite en la materia del derecho de los consumidores ${ }^{39}$. Es decir, se contempla el fenómeno del "sobreendeudamiento" o insolvencia de personas naturales como un caso de regulación especial que no puede dejarse librado a la suerte del trato igualitario sin reservas. Un segundo supuesto a mencionar, ahora en contraste con la igualdad de trato a los acreedores dentro de la ejecución civil francesa es una excepción expresa a él mediante la "saisie-attribution" (embargo ejecutivo) como medida asimilable al embargo ejecutivo que recae

Recht - ein Vorbild für das schweizerische Recht? en Zeitschrift für Schweizerisches Recht (2006) 1, pp. 563 ss.

${ }^{37}$ Chardon, Mathieu, Enforcement in France, in van Rhee, Remco - Uzelac, Alan, Enforcement and Enforceability. Tradition and Reform (Oxford, Intersentia, 2010), pp. 147 ss.

${ }^{38}$ Para un estudio histórico: BRISSAUD, Jacques, Le creancier "premier saisissan" dans l ancien Droit français (Paris, Presses Universitaires de France, 1972), p. 19.

${ }^{39}$ Crítico Terré, François., Droit de la fallite ou fallite du droit, en Revue de Jurisprudence Commercial (1999), pp. 1-29. 
sobre créditos, bienes muebles y dinero ${ }^{40}$. Es más el acreedor ya podría ser él pagado en su totalidad excluyéndose todo concurso si tenía una "saisieconservatoire" (embargo preventivo) ${ }^{41}$.

Es que con ella el acreedor rompe con la regla del artículo 2093 del Código Civil francés que impone comunidad de beneficios y pérdidas como resultado de la igualdad ${ }^{42}$. Finalmente el último caso a considerar es una excepción a la prelación que otorga la "saisie-attribución" cuando lo afectado son sueldos y remuneraciones del ejecutado, ya que en ese caso vuelve a regir la igualdad que excluye la prelación ${ }^{43}$. Ello se justifica por ser ingresos del deudor de tal importancia para su mantención que conviene queden a disposición de todos los acreedores por las limitaciones legales en relación al porcentaje embargarle y con ello impedir que, a costa del deudor y sus ingresos, se pueda satisfacer un acreedor en perjuicio de los otros. De esta forma al principio general de igualdad de trato se establece una excepción que otorga prelación o prioridad: es el embargo de créditos que titularice el deudor excluyendo a aquellos que sean salarios o remuneraciones ${ }^{44}$.

En el sistema francés las reformas del siglo XX y XXI se fundaron en cuenta consideraciones en la etapa de realización, liquidación y especialmente distribución. Mediante la "répartition des derniers", se procura dar pie

${ }^{40}$ En detalle: Perrot, Roger - Thery, Philippe, Saisie attribution: la situation du tiers saisi (arrêts 5.7. 2000) (Paris, Dalloz, 2001), p. 716. Así desde la reforma de 1991 se permite que el acreedor beneficiado con una "saisie- conservatoire" del crédito puede ser pagado. La doctrina ve allí una imposibilidad de concurrencia, ya que la atribución patrimonial del pago consuma la medida conservativa como el interés de ese acreedor beneficiado no llegándose a un "concurso", véase al respecto: Donnier, Marc - DonNIER, Jean-Baptiste, cit. (n. 32), pp. 184 s.

${ }^{41}$ Lefort, Christopher, Saisie-attribution, en Repertoire de Procedure Civile (Paris, Dalloz, enero de 2007), pp. 1-73.

${ }^{42}$ Delmotte Philippe, L'égalité des créanciers dans les procédures collectives, visible en : www.courdecassation.fr [visitado el 11 de diciembre de 2010].

Cfr. Miniato, Lionel, Voies d'exécution et procédures de distribution (Paris, 2009), pp. $5-40$

${ }^{43}$ Girard Pierre-André - Prohaszka Jean-Pierre, La détermination des droits des créanciers saisissants en cas de concours, en La Semaine Juridique, Notariale et Immobilière, 12 (marzo de 2003), p. 464.

${ }^{44}$ Lienhard Alain, Saisie-attribution de créances à exécution successive: leffet attributifplus fort que légalite des créanciers, en Observations sous Cassation Chambre Mixte (22 noviembre 2002). El examen diferenciado según sea el crédito embargado a favor del acreedor laboral (que puede cobrarse inmediatamente y con ello ese crédito queda fuera del patrimonio del ejecutado), véase: el embargo de un crédito laboral siendo técnicamente postergado el acreedor para su cobro, puede verse en: GARREAU Christophe, La saisie-attribution, la procédure collective et la date de naissance des créances contractuelles, en Revue Trimmestrale de Droit Commercial, 3 (2004), p. 414. 
inicial al acuerdo entre los acreedores para la distribución con disminución del nivel de litigiosidad y desjudicializando la actividad. Justamente este procedimiento parte de la concurrencia de acreedores y (aunque no refiere técnicamente a la insolvencia) a la imposibilidad del ejecutado de satisfacer todos los créditos (muy similar a los mecanismos existentes en algunos países denominado "tercería de pago" para lo cual se debe determinar el prorrateo en base al monto de cada crédito. En base a una propuesta de distribución se pone en conocimiento a los acreedores y se insta a una conciliación si no hay directa aprobación. En caso de fracaso, quedan fijadas las bases para un contencioso futuro ${ }^{45}$.

Como puede verse la solución francesa es coherente en la repartición con el principio de igualdad o contribución. El resultado probable de un acreedor con garantía real es que se satisfaga en su crédito totalmente, mientras que los valistas deben soportar la eventualidad de la concurrencia y el riesgo de insuficiencia para el pago. Esta aplicación concreta del principio de igualdad debe diferenciarse de la "insolvencia civil o de consumidores" ("traitement des situations de surendettement”), donde sí se trabaja con la superación del pasivo a los activos del deudor sobreendeudado de buena fe para hacer frente a sus obligaciones en las relaciones crediticias de consumo ${ }^{46}$. Este procedimiento fundado en la insolvencia personal procura impedir la exclusión absoluta del deudor en su ámbito económico y se fortaleció con la última reforma del 2010 para fortalecer e incentivar a reordenar o "reorganizar repactando" sus obligaciones y paralelamente no suspende en principio las ejecuciones singulares. El deudor se somete a un control judicial de su estado y en contraste con las proyecciones podría darse lugar a la suspensión de las ejecuciones ${ }^{47}$.

\section{SISTEMA DIFERENCIADO POR PRELACIÓN TEMPORAL: EL PRINCIPIO DE PRIORIDAD}

Siempre que el principio de prelación temporal rija en un sistema de ejecución civil, tendrá por consecuencia precluir la posibilidad de actos de afectación posteriores sobre los bienes del patrimonio, así el primer embargo

${ }^{45}$ Fricero, Natalie, Procédures civiles d'exécution: Voies d'éxecution, procédures de distribution (París, 2010), pp. 147 ss.; Donnier, M. - Donnier, J. B., cit. (n. 32), pp. $523 \mathrm{~s}$.

${ }^{46}$ Bourin, Vincent - Vigneau, Guillaume, Droit du surendettement des particuliers (Paris, Litec, 2007), pp. 10-35

${ }^{47}$ BÉGUERI, Mark, Le dispositif de traitement des situations de surendettement des particuliers: les principaux effets de la loi Lagarde, en Bulletin de la Banque de France, 182 ( $4^{\circ}$ trimestre de 2010), pp. 59 ss. 
constituye un "gravamen" que impide otros posteriores. La explicación lógica parte de que el mejor de los derechos es el primero y quienes concurran con aquel nada podrían recibir, salvo que hagan valer un derecho aún más preferente. De esta forma el principio de prelación comprende dos premisas: una enuncia que aquel quien ejerce sus derechos oportunamente en comparación con otros posteriores debe ser satisfecho en plenitud; en segundo lugar aquel que no ejerce su derecho oportunamente sólo puede satisfacerse en su crédito por el remanente.

No resulta simple fijar los criterios para determinar el momento en el cual la prioridad o prelación temporal va a ser reconocida a determinado acreedor en relación y contra de otros en la ejecución civil. Podríamos muy bien partir del momento en el cual se efectiviza la primera medida de agresión ejecutiva como es el embargo, pignoración o hipoteca judicial ${ }^{48}$. Desde entonces se cerraría la posibilidad de que el primero en ejercer su derecho de crédito pueda verse afectado por acreedores concurrentes posteriores y por ende postergados. En otros términos deberán ver satisfecho su crédito con el remanente luego de la realización de los bienes necesarios para la satisfacción íntegra del acreedor que previno.

En el derecho germano y anglosajón se veía ya históricamente con buenos ojos el reconocimiento de dicho principio como una suerte de "privilegio" en favor del acreedor diligente ${ }^{49}$. Históricamente los tribunales de Nueva York aplicaron el principio de prelación para no dejar sin protección a quien oportuna y diligentemente instó la ejecución y obtuvo en su favor una medida de resguardo patrimonial de un deudor común a otros acreedores que optaron por actuar con posterioridad ${ }^{50}$. De lo contrario se estaría indirectamente beneficiando e incentivando a aquellos acreedores que difirieron o dejaron pasar el tiempo para ejercer sus derechos ${ }^{51}$. Es comparativamente interesante la exposición de motivos del "Proyecto de Código Procesal Civil” para el imperio alemán de 1879 en tanto se refería a la "impostergable necesidad de introducir la prelación o prioridad por razones de justicia y de respeto al acreedor que velaba por sus derechos y cuando eran exigibles,

${ }^{48}$ Kroener, William, Expanding FDIC-Style Resolution Authority, en Ending Government Bailouts As We Know Them (2010), p. 182 ("bankruptcy provides clearer rules on creditor priorities").

${ }^{49}$ Ayotte Kenneth - Skeel, David, Bankruptcy or Bailouts? en Journal of Corporate Law, 35 (2010), pp. 469, 488.

${ }^{50}$ JaCkson, Thomas Skeel, David, Bankruptcy, Banks, and Nonbank Financial Institutions (Wharton Fin. Inst. Cent. Workshop, Feb. 8, 2010)

${ }^{51}$ Críticas a ciertas injusticias en la aplicación del principio de prelación pueden verse en McCullough, When First in Time is not First in Right, en Loyola University Chicago Law Journal, 25 (1994), p. 405. 
instaba por su cumplimiento". Sí, agrega un nuevo y elocuente argumento, cual es la necesidad de que el legislador distribuya con equidad el momento de solvencia o posibilidad de pago del deudor, para que no sea el acreedor diligente quien soporte el riesgo de la insolvencia ${ }^{52}$.

Tanto la ejecución en Austria ${ }^{53}$ como en Alemania parten de la premisa de la efectivización del primer embargo como momento en el tiempo que otorga prioridad frente a ejecuciones sucesivas contra los mismos bienes del deudor. Curiosamente en Alemania las disposiciones que instruyen a los oficiales de ejecución contienen una regla en su $₫ 168$ numeral uno que se aparta de la relación o prioridad temporal. Dicha disposición establece que el oficial de ejecución a quien se solicita por varios acreedores el embargo contra el mismo deudor, debe dar un tratamiento igualitario a todas las peticiones, y por ende se considerará todos los embargos ejecutivos solicitados como si generaran efectos desde un mismo momento.

En realidad dicha disposición determina, imponiendo al oficial de ejecución el tratamiento igualitario de las peticiones o solicitudes de embargo ejecutivo donde no rige la prelación, ello por que deben distinguirse los momentos de inicio de la ejecución, con la solicitud de un embargo ejecutivo, del momento en el cual aquél se efectiviza. Esta disposición instó a que parte de la doctrina viera un resabio de la comunidad de pérdidas del tratamiento igualitario de los acreedores en la ejecución civil alemana en contraste con la disposición expresa del $\$ 804$ incisos $3^{\circ}$ del Código Procesal Civil ${ }^{54}$. En el caso de Grecia es discutida la existencia de la prelación versus igualdad de trato, aunque la imposición legal impide posteriores embargos sobre el mismo bien del deudor. Ello si bien no establece prioridad o prelación, sí indirecta y negativamente impide la superposición de embargos sobre un mismo bien (artículo 973 CPC. griego) ${ }^{55}$. Debe incluirse igualmente el nuevo

${ }^{52}$ Sobre las bases de la prelación en el Derecho romano véase: WEISL, Ernst, Deutsche Pfandrecht bis zur Reception des Romischen Rechtes (Viena, 1881), pp. 29-31.

${ }^{53}$ Para la prelación en general véase: Rechberger, Walter - Oberhammer, Paul, Exekutionsrecht (Viena, Facultas, 2010), pp. 3 s. y 180; KoneCNY, Andreas, Konkurs ist ein Konkurs ist ein Konkurs, en Festschrift Rechberger (Viena, Spring, 2005), pp. 301316, esp. 306-313.

${ }^{54}$ KLAMARIs, Nikolaos, Zum Stand des griechischen Zwangsvollstreckungsrechts: eine zusammenfassende Skizze, en Zeitschrift für Zivilprozess, 121 (2008), pp. 475-502.

${ }^{55}$ Orfanidis, Georgios, Die Konkurrens von Gläubigern im griechischen Zwangsvollstreckungsrecht. Grenzüberschreitungen: Beiträge zum internationalen Verfahrensrecht und zur Schiedsgerichtsbarkeit, en Festschrift für Peter Schlosser zum 70 Geburtstag (Tübingen, Mohr Siebeck, 2005), pp. 669-681; Maniotis, Dimitris, en STÜRner, R. -Kawano, M. (directores), Comparative Studies on Enforcement and Provisional Meassures (Tübingen, Siebeck, 2011), pp. 68 ss. esp. p. 71 . El sistema que rige en Grecia por un lado no concede preferencia o prelación alguna al primer acreedor embargante 
sistema inglés donde la prelación es la regla frente al caso de deudor común solvente ${ }^{56}$. Igualmente se aplica la prelación entre otros en Hungría, como ejemplo claro de países miembros ${ }^{57}$.

El embargo es en esencia un medio destinado a concretar sobre bienes determinados el principio de responsabilidad patrimonial universal. Técnicamente no constituye un derecho real y menos es aceptable a sostener que otorgaría una acción reipersecutoria. Tampoco califica al crédito en virtud del cual se ejerce. Solamente localiza, identifica y sujeta un bien determinado a una ejecución concreta. La distinción entre embargo preventivo y ejecutivo, y en este último identificando aquellos casos donde hay anotación registral, en realidad es la anotación la que atribuye prelación temporal a ese crédito y no el embargo mismo (artículo 1923 inciso $4^{\circ}$ CCesp.) $)^{58}$. En Portugal ${ }^{59}$ de la misma forma el principio de prelación que otorga el derecho al primer.

aunque el Código prohíbe expresamente el embargo, sí la realización del bien puede beneficiar a otros acreedores, suponiendo que todos son quirografarios y ninguno detenta un derecho real de garantía. Sobre el sistema griego en posición discutida, puede verse: Yessiou-Faltsi, Pelaya - Pipsou, Linda, Seizure and Overindebtedness in the European Union, en DE Leval, G. (director), Seizure and Overindebtedness, cit. (n. 27), pp. 391 ss.

${ }^{56}$ Andrews, Neil - Turner, Robert, en van Rhee, Remco - Uzelac, Alan, Enforcement and Enforceability- Tradition and Reform (Oxford, Intersentia, 2010), pp. 127 ss.

${ }^{57}$ Kengyel, Miklós - HARSÁgi, Viktoria, “Generalbericht”, en Los mismos (directores), Grenzüberschreitende Vollstreckung in der Europäischen Union (München, Sellier, 2011), pp. 414 s., sostienen -correctamente- que el embargo o "congelamiento" de cuenta bancaria genera prelación solo si se funda en un título ejecutivo y no como mera medida cautelar fuera de un procedimiento de ejecución. Incluso sería correcto hablar de "embargo", en tanto el saldo activo de la cuenta afectada es transferido por la entidad financiera a la cuenta del tribunal o del oficial de ejecucicón interviniente, mientras que el congelamiento implica solo la prohibición de administrar o disponer generando movimientos en la cuenta.

${ }^{58}$ Díez Soto , Carlos Manuel, Concurrencia y prelación de créditos: teoría general, Madrid, 2006), pp. 11, en relación con la responsabilidad patrimonial universal del deudor (artículo 1911 CCEsp.); no hay razón para la limitación frente a un ejecutado solvente y todos los acreedores en igualdad de condiciones deberían verse satisfechos de sus créditos en la totalidad. La diferente clasificación de los créditos existiendo concurrencia de acreedores frente a un deudor solvente (p. 23) tiene utilidad en la ejecución singular solo si los acreedores ejercieran un proceso para que se declare sus derechos a ser pagados con prelación a otros acreedores frente a un deudor común ejecutado..

${ }^{59}$ Sobre el sistema de prelación portugués Lebre de Freitas, José, Seizure and Overindebtedness in the European Union, en DE LeVAL, G., (director), Seizure and Overindebtedness, cit. (n. 27), pp. 505-509. 


\section{SisTEMA DE TRATO ISONÓMICO POR PRELACIÓN:} EL PRINCIPIO DE AGRUPAMIENTO O CLASES

Una solución intermedia de prelación y de trato igualitario está representada por el principio de agrupamiento o clases de acreedores. Alternativa combinada, ya que parte del tratamiento igualitario a los acreedores que ejercen sus derechos dentro de un determinado plazo recibiendo un trato preferente a aquellos que inician la ejecución con posterioridad ${ }^{60}$.

De esta forma se establecen plazos en el tiempo dentro de los cuales se van conformando las distintas clases de acreedores donde los primeros son preferidos en relación a los posteriores. Así reciben el mismo trato todos los acreedores que dentro de un determinado espacio de tiempo hayan obtenido un embargo en su favor. Por ejemplo los sucesivos embargos de bienes dentro de un plazo luego de perfeccionado el primero en la ejecución iniciada, son tratados en forma igualitaria. Ahora ese grupo o clase conformada por los acreedores que hagan valer sus derechos en ese plazo son preferidos a los que lo ejerzan con posterioridad. Prioridad del sistema combinado de ordenación por grupos existe en el derecho ejecutivo civil suizo como así también en algunos estados de los Estados Unidos como Nebraska ${ }^{61}$.

La ley que regula la ejecución de las obligaciones en Suiza en su artículo 110 establece la conformación de grupos de acreedores de acuerdo a un criterio temporal dentro de determinados plazos. Así los acreedores se agrupan a partir del primer embargo ejecutivo dentro de los 30 días para la conformación de un grupo de acreedores dentro del cual rige el principio de tratamiento igualitario o de comunidad de pérdidas. Aquellos embargos que se efectúan con posterioridad al mencionado plazo conformarán un segundo grupo y así sucesivamente ${ }^{62}$. En cierta manera es el sistema que rige también

${ }^{60}$ STAMM, cit. (n. 17), pp. 160-165

${ }^{61}$ Pajic, Natasa, Enforcement and Execution in the USA, en VAN RHEe, Remco - Uzelac, Alan, Enforcement and Enforceability. Tradition and Reform (Oxford, Intersentia, 2010), pp. 237-250 y nota 401. En los Estados Unidos de América la mayoría de los estados federales adoptaron el principio de prelación o de prioridad, incluso el estado de Luisiana -conocido por la fuerte recepción sustantiva y procesal del Derecho francés- su Código Procesal Civil establece la prioridad en el artículo 2292: " Privilege of creditor on seized property; successive seizures: $A$. To the extent not otherwise governed under Chapter 9 of the Louisiana Commercial Laws (R.S. 10:9-101, et seq.), a seizing creditor, by the mere act of seizure, acquires a privilege on the property seized, which entitles him to a preference over ordinary creditors. B. When several seizures of the same property are made by ordinary creditors, the seizing creditors acquire a privilege and are entitled to a preference among themselves according to the order of their seizures".

${ }^{62}$ Meier, Isaak, Die dogmatische Situation des Vollstreckungsrechts aus der Sicht des schweizerischen Rechts, en Zeitschrift für Zivilprozess, 121 (2008), pp. 295-350; una 
en el derecho griego donde, sin embargo el establecimiento de relaciones o derecho con prioridad se manifiesta con tantas excepciones que la aplicación de la comunidad de pérdidas o tratamiento igualitario termina con cierta dificultad de aplicación ${ }^{63}$. Dicho fenómeno también se manifiesta en Suiza mediante el establecimiento de determinadas relaciones que asumen calidad semejante a los privilegios dentro del concurso otorgando preferencia a determinados acreedores.

A ello se le suma la conformación mediante reformas posteriores de nuevos privilegios que implican establecer diferencias de trato dentro de los grupos o clases de acreedores ${ }^{64}$. En la práctica constituye un pequeño concurso de acreedores frente a un deudor que no es comerciante y por ende no puede ser sometido a las normas que regulan la ejecución universal adscriptas al derecho mercantil concluye, a diferencia del modelo francés, sin una vinculación, motivación o justificación relacionada con el derecho sustantivo ${ }^{65}$.

\section{LA UNIDAD DE ANÁLISIS DE LA EJECUCIÓN (UNIVERSAL Y SINGULAR)}

Parece no revestir enorme complejidad arribar a una noción, individualización normativa de presupuestos y consecuencias de la ejecución civil, como tampoco parecen serlo los de la ejecución universal, debiera plantearse si es posible brindar una noción omnicomprensiva que justamente logre plasmar los elementos comunes y diferenciadores de un tipo y otro de eje-

versión actualizada puede verse en Aktuelle Probleme der Zwangsvollstreckung aus Sicht des schweizerischen und türkischen Rechts, en Blätter für Schuldbetreibung und Konkurs (2010), pp. 1-34

${ }^{63}$ Ya una publicación anterior centrando la atención en la insolvencia personal como fenómeno no escindible de la concurrencia de acreedores en la ejecución individual puede verse. Meier Isaak - Zweifel Pete - Zaborowski Christoph - JentSøRENSEN Ingrid, Auf der Suche nach dem optimalen Existenzminimum, eine rechtliche und ökonomische Analyse der Einzelzwangsvollstreckung gegen Privatpersonen in der Schweiz mit Erarbeitung von Reformvorschlägen, en Blätter für Schuldbetreibung und Konkurs (1998), pp. 195 ss.; más actual MeIER Isaak - Perrier Camille, Sanierung und Entschuldung von Privatpersonen nach französischem Recht. Ein Vorbild für das schweizerische Recht? en Zeitschrift für Schweiserisches Recht (2006) 1, pp. 563 ss.; STAMM, cit. (n. 17), pp. $164 \mathrm{s.}$

${ }^{64}$ Amonn Kurt - WALTHER Fridolin, Grundriss des Schuldbetreibungs- und Konkursrechts (7a edición, Berna 2010), $\$ 19$ n. 22; SP ÜHLER Kar - GEHRI Myriam, Schuldbetreibungs-und Konkursrecht (Züric - Basel - Genf, 2008), p. 78.

${ }^{65}$ Visión de Cavalier, Georges, The French Bankruptcy, en Stürner, R. -Kawano, M. (directores), Comparative Studies on Enforcement and Provisional Meassures (Tübingen, Siebeck, 2011), pp. 163 ss. 
cución. Ello permitiría una adecuada política legislativa procesal-sustantiva de ambas situaciones entrelazadas y relacionadas y no en forma autónoma o indiferente una de otra.

\section{La ejecución singular y su relación con la universal.}

La ejecución civil singular podría conceptuarse como el procedimiento ante la injustificada negación al cumplimiento de una prestación a través del cual se busca quebrantar la voluntad del deudor con reserva del ejercicio de la fuerza por parte del Estado. Un conjunto de otras definiciones incluyen la satisfacción del crédito del ejecutante o acreedor como así también la realización del patrimonio del ejecutado. Ambos elementos no son pues imprescindibles en la ejecución civil, ya que por un lado puede no llegarse necesariamente la realización del patrimonio (con corrección de ciertos bienes que lo integran): así por ejemplo en el caso de una obligación de hacer previa imposición de una medida coercitiva de naturaleza patrimonial cuando el deudor efectivamente cumple con la misma; o en una obligación de pagar una suma de dinero cuando la misma es embargada en una cuenta bancaria y se ordena el pago al acreedor ${ }^{66}$. Tampoco puede decirse con corrección que en toda ejecución civil se obtenga la satisfacción del crédito. El crédito que titularizar por concepto de la obligación podría estar marcado por un interés en particular como ser de oportunidad, tempestividad o especialidad lo que muchas veces resulta ciertamente irrelevante para la ejecución civil. Pero aun con las reservas en relación a distintas nociones sobre ejecución civil singular podríamos tomar sólo a modo de ejemplo una noción de ejecución universal, como el procedimiento en caso de insolvencia con concurrencia de acreedores que tiene por objeto la satisfacción común e igualitaria de los acreedores mediante la afectación del patrimonio de un deudor en estado de insolvencia ${ }^{67}$.

De esta forma pueden mencionarse tres características propias de la ejecución universal: en primer lugar está impregnada por el principio de trato igualitario de los acreedores o comunidad de pérdidas; en segundo lugar mientras la ejecución civil singular afecta una parcela del patrimonio del ejecutado, la ejecución universal implica justamente la afectación de una universalidad jurídica (patrimonio) del deudor; en tercer lugar el requerimiento de la existencia de un título ejecutivo y los mecanismos de conformación del mismo suelen ser mucho más estrictos en la ejecución civil singular que en la universal, regulándose en esta última un procedimiento de verificación de

${ }^{66}$ STAMM, cit. (17), pp. $168 \mathrm{s.}$

${ }^{67}$ Rosenberg, Leo - Gaul, Hans - Schilken, Eberhard - Becker-Eberhard, Ekkehard - PANAjotta Lakkis, Zwangsvollstreckungsrecht (München, 2010), pp. 16 s. 
créditos o de comparecencia de los acreedores dentro de un período de tiempo para que hagan valer sus créditos, los que no necesariamente deben estar documentados. El monopolio del uso de la fuerza en la agresión patrimonial en la ejecución por parte del Estado se manifiesta también en la ejecución universal a través del cauce procedimental (leyes de insolvencia, concursos o quiebras) mediante las cuales queda sujeto la totalidad del patrimonio del ejecutado para su administración y eventual realización para la satisfacción igualitaria de los créditos que se hicieron valer ${ }^{68}$.

Podría muy bien decirse que en la ejecución universal sin embargo, los mecanismos de incentivo negativos y positivos vinculados a la autonomía de la voluntad especialmente de los acreedores son mucho más fuertes: varias son las decisiones que se toman colegiadamente (juego con estrategia cooperativa antes que competitiva), los acuerdos individuales de un acreedor para con el ejecutado universal no son oponibles a los restantes acreedores. Es justamente en la insolvencia donde toman una especial importancia y comienzan a desempeñar su rol las preferencias crediticias (juego con estrategia competitiva antes que cooperativa). Ellas contienen determinadas características vinculadas con el crédito que se pretende ejecutar al cual otorgan cierta prelación para ser pagados con prelación a otros. Siendo que en la ejecución universal rige el principio de trato igualitario de los acreedores, la preferencia crediticia debe fundarse después en otras causales o criterios que no son estrictamente temporales. Tiene así el derecho concursal en la ejecución universal un contenido más de naturaleza sustantiva que justamente determina cómo, cuándo y por qué motivo debieran cumplirse determinadas prestaciones postergándose otras. Es curioso como sistemas de ejecución civil singular como el italiano en el cual rige, en forma similar a la ejecución universal el tratamiento igualitario de los acreedores, establece por ejemplo en el artículo 2741 del código civil italiano supuestos de grupos de acreedores privilegiados y preferencias que están pensadas no sólo para la ejecución universal, sino para el caso de concurso de acreedores en la ejecución civil singular.

Recordemos que la doctrina alemana minoritaria se manifestó contra el principio de prelación o de prioridad temporal. Debemos decir que dichos argumentos sustentan y son perfectamente aplicables a la ejecución universal donde el trato igualitario de los acreedores frente a un patrimonio insuficiente para responder y satisfacer créditos concurrentes debe hacerlo como patrimonio universal con el reconocimiento de otros criterios de prelación por su naturaleza real o carácter alimentario o de importancia existencial.

${ }^{68}$ STAMM, cit. (17), pp. 169 ss. 


\section{El rol de la regulación de la concurrencia de acreedores y la insolvencia.}

La ejecución universal comprende un conjunto de disposiciones de naturaleza procesal y sustantivas para el desenvolvimiento, determinación y manejo de una universalidad cual es el patrimonio del ejecutado (insolvente, fallido) en sus relaciones económicamente afectadas y que se sujetan al control de un proceso judicial preestablecido. Esta noción de derecho concursal universal, rectius: derecho de la insolvencia universal, permite incluir no sólo aquellas normas netamente procesales, sino también las de naturaleza sustantiva directamente vinculadas a la regulación de todas las relaciones patrimoniales del insolvente en calidad de deudor o de acreedor. El derecho concursal que refiere solo a la pluralidad de acreedores contra un deudor común, resulta así insuficiente ya que como vimos, también se podría verificar dicha situación en el caso de la ejecución civil singular donde se da el supuesto no sólo de la pluralidad de acreedores, sino también la condición patrimonial del deudor.

Cuando me refiero a la "insolvencia" como estado o fenómeno del patrimonio deudor que puede darse dentro de una ejecución singular como universal con acreedores que concurren. A lo segundo aludo empleando indistintamente los términos de ejecución universal o insolvencia, para diferenciarla de la singular ${ }^{69}$. En ambos casos nos interesa la regulación del concurso de acreedores y su combinación actual o eventual con una insuficiencia patrimonial del ejecutado común para satisfacer todos los créditos ejercidos en su contra. La regulación de la ejecución universal comprende la responsabilidad patrimonial universal del ejecutado en favor de un colectivo de acreedores para permitir distribuir un patrimonio insuficiente para una satisfacción íntegra de todos los créditos invocados. Este procedimiento a través del cual una universalidad (patrimonio) pasa a disposición de los acreedores, se realiza a través de un procedimiento con participación mayor o menor de los tribunales de justicia, estamos frente a un proceso judicial a través del cual se encauzarán el conjunto de relaciones sustantivas y procesales del ejecutado universal. El derecho de la insolvencia en la ejecución universal (o derecho concursal, o quiebra) tiene por objeto el examen y determinación de responsabilidades y sustentabilidad de las relaciones patrimoniales titularizadas por el ejecutado. Está sujeta a una serie de interrogantes de naturaleza económica, social, y jurídicas que van a surgir de la tensión existente entre la posición del deudor ejecutado y la necesidad de la satisfacción de los créditos

${ }^{69}$ Reifner, Udo - Nieme, Kiesiläine - Huls, Nik - Springeneer, Helga, Overindebtedness in European Consumer Law: Priciples from 15 European States (London, POd, 2010), esp. pp. 5-20. 
en lo posible e idealmente en forma igualitaria traducida en proporciones de aquellos y nunca en su totalidad.

Como antecedente histórico, recordemos que en el Reino Unido, antes de la promulgación de la Ley de fallidos de 1542, no existía régimen unificado de tratamiento de deudores en insolvencia frente a acreedores concurrentes. El paso dado estaba marcado por una situación de excepción que ameritaba una ficción de igualdad de trato de los acreedores para una satisfacción proporcional de sus créditos que implicó la adopción de la regla pari passu para realización y distribución de los activos liquidados, esa fue desde entonces la característica e insignia de la quiebra o ejecución universal ${ }^{70}$. El desarrollo progresivo del comercio y la necesidad de resguardo de los créditos instó a que paulatinamente se fuera organizando la administración de los bienes de la quiebra para garantizar el tratamiento equitativo de todos los acreedores. Era justamente la situación de insolvencia del deudor partícipe del comercio que imponía la igualdad de trato de los acreedores y que marcaba la diferencia con las ejecuciones individuales aun con pluralidad de interesados pero sobre un patrimonio solvente. Con la Ley de liquidación de empresas de 1844 llegó a consolidarse como en casi toda Europa un derecho de la quiebra para los comerciantes o empresas. Ya hasta entonces habían tomado un rol protagónico las juntas de acreedores. Paulatinamente el sistema se tornó solo útil para los acreedores mayores que terminaban desplazando en las decisiones (e intereses) a los menores). Era evidente que los acreedores más débiles quedaban a merced de los más fuertes y con elevada probabilidad de ver insatisfechos sus créditos ${ }^{71}$. Así la nueva ley venía no solo a llenar un vacío de regulación integral de la quiebra, sino además a evitar las situaciones inequitativas que se daban en el trato de los acreedores a instancia de los más poderosos, vulnerando en definitiva la igualdad de chance y trato al cual todos tenían derecho. Ello unido a la regulación de las sociedades comerciales y su responsabilidad incentivó a que en forma cada vez más frecuente los deudores (la sociedad) debieran otorgar garantías justamente pensando en la eventualidad de la insolvencia. Así es que se comenzaron a distinguir los acreedores no ya por la cuantía del crédito, sino por tener o no su crédito garantizado. Éste fue entonces el criterio adoptado por la ley para establecer tratos preferenciales a determinados acreedores sobre otros. Era más previsible y de alguna forma un incentivo a la debida diligencia del acreedor para exigir ciertas garantías actuando ante una eventualidad. De hecho la Ley de sociedades de 1862 fue pionera es garantizar el pago primero a los acreedores

${ }^{70}$ Finch, Vanessa., Is Pari Passu Passe? en Insolvency Lawyer (2000) 5 (octubre), pp. 194-210.

${ }^{71}$ Armour, John - Walters, Adrian, Funding Liquidation: A Functional View, Law Quaterly Review. 122, (2006), pp. 295-326. 
con garantía real frente a otros quirografarios. El posterior incremento comercial e industrial como el desarrollo del derecho de las sociedades sentó las bases para distinguir entre la ejecución universal de las sociedades (quiebra) del trato a las empresas individuales (insolvencia). Paralelo a ello se fueron constituyendo diferentes tipos de prelaciones legales que volvieron cíclicamente a marcar diferencias injustas entre los acreedores ${ }^{72}$.

La dinámica misma del procedimiento concursal con su apertura, desenvolvimiento, alternativas de liquidación, saneamiento o transferencia de parte del patrimonio permite en mayor o menor medida la intervención del Estado a través de la función jurisdiccional directa o indirectamente en los funcionarios delegados para ejercer los roles de síndicos o administradores. El rol de los acuerdos y los centros de intereses en la ejecución universal terminan siendo decisivos para el éxito o fracaso del sistema concursal regulador de la insolvencia. Permitiendo el mayor peso de los acreedores (junta de acreedores) o su organización por clases a los efectos de permitir la toma de decisiones colegiadas, la habilitación o no de juntas de acreedores no privilegiados o de aquellos que tienen determinado tipo de relación patrimonial con el ejecutado como una relación laboral, pueden dar lugar a una más o menos eficiente tratamiento del patrimonio insolvente. Pero en ningún caso puede dejarse de asignar un rol al no observando quizás que con ello se terminen satisfaciendo sólo determinados acreedores y eliminándose del mercado al ejecutado. A ello se puede combinar un papel más o menos proactivo del ejecutado. Así podrían darse casos en los cuales se priorice el saneamiento y continuidad del ejecutado en su giro en lugar de la realización y liquidación de su patrimonio para pagar al mayor número posible de acreedores con el costo socio-económico para un deudor y su entorno al ser de hecho (cuando no de derecho) excluido del mercado.

Aunque la discusión doctrinaria por la pertenencia del derecho concursal o de la insolvencia al derecho privado o al derecho público ha seguido los mismos derroteros de la dada en torno al procesal civil, no pueden dejar de considerarse las especificidades antes planteadas y en especial el carácter fuertemente bifronte de la ejecución universal. El grado de intensidad del examen constitucional de las distintas alternativas en el proceso concursal universal podrá ser mayor o menor según sea la materia ordenada al derecho público o privado. Una primera respuesta aceptable en el examen del contenido de las normas concursales no permiten identificar disposiciones al menos netamente procesales, por el contrario serían mayor las de contenido sustantivo. Son justamente estas últimas, referidas al derecho mercantil, civil,

${ }^{72}$ Finch, Vanessa, The Recasting of Insolvency Law, The Modern Law Review. (2005), 68(5), pp. 713- 736. 
laboral principalmente, las que se encuentran sometidas completamente al derecho privado, aplicándose la norma procesal concursal sólo en aspectos determinados para ser sometidos al resguardo y control de los intervinientes para la legitimidad y control de los actos.

No pueden dejarse de reconocer los derechos patrimoniales enfrentados, no sólo del deudor con sus acreedores, sino de los distintos acreedores entre sí. Ello permite diferenciar los variados casos, relaciones y estados procesales para una aplicación de la proporcionalidad a los distintos intereses en juego de la forma menos gravosa posible y más adecuada para el resguardo del interés prevalente en juego. Justamente es en la ejecución universal como singular donde resultan concretos y perceptibles los resultados de suma cero, positiva o negativa aplicando teoría de los juegos. Así podría muy bien preguntarse quién gana, quién pierde en cada uno de los modelos descriptos. Las normas que regulan la adopción de decisiones colegiadas, sean de los acreedores de una clase o de todos los acreedores entre sí, imponen que el legislador justifique la razonabilidad de dichas disposiciones pudiéndose controlar no sólo la eficiencia sino también los intereses que serán positiva, neutral o negativamente afectados. La combinación de incentivos negativos y positivos para la obtención de determinado resultado dentro del procedimiento concursal se termina traduciéndo una regulación dónde la previsibilidad, transparencia y equidad del sistema asumen un rol protagónico no solo para los intervinientes directos, sino para quiénes podrían ser afectados por las externalidades del modelo.

Podría sin embargo encontrarse un punto de contacto y quizás armonizador entre la ejecución civil singular y la universal a partir de la consideración de la naturaleza del crédito o prestación a ejecutar. De esta forma sería posible explicar la justificación de la aplicación del principio de prioridad o prelación en determinados supuestos frente al de comunidad de piedad de pérdidas o de trato igualitario de los acreedores que no. Incluso el principio de prelación ofrece también ventajas desde el punto de vista de la previsibilidad del crédito y su tutela para cada uno de los acreedores. Resguardo ejecutivo mediante el embargo asume por ello un trato prioritario en relación a otros posibles acreedores concurrentes de calidad y actuación aún incierta desde el punto de vista del deudor. Ello impide en alguna medida la posibilidad del sobre (re)embargo sobreabundante, siendo que ya hay certeza sobre la insuficiencia de una parte del patrimonio para la satisfacción de los crédito concurrentes. Indirectamente el principio de prioridad o prelación establece una solución anticipada a la concurrencia de acreedores en la ejecución civil singular (asumiendo incluso y según la visión de importante posición en la doctrina griega), ello debido a que el bien embargado no sería reembargable por no poderse aplicar un "gravamen", sino una solo vez. Solo el sobrante 
podría quedar sujeto al concurso de los restantes acreedores. Ello coadyuva de alguna medida en la determinación de los sujetos de la ejecución civil singular especialmente desde la posición de los acreedores ejecutantes.

Difiere la situación en la ejecución universal en la cual la universalidad del patrimonio se sujeta a un procedimiento para la satisfacción de un concurso de acreedores sabiendo de antemano que sus créditos no podrán ser satisfechos en su totalidad. En este ámbito sí se justifica el acudir a mecanismos y justificaciones del derecho público no sólo desde el punto de vista constitucional para el resguardo de la dignidad y los requisitos existenciales mínimos del ejecutado y su entorno, sino también las consideraciones sociales y de costos que podría asumir la exclusión de un sujeto del mercado laboral como así también del tráfico ordinario. Los costos sociales son en dicho caso también asumidos directa o indirectamente como co-partícipe para contribución en pérdidas y beneficios ${ }^{73}$. De esta forma la pretendida antinomia y enfrentamiento con una visión polarizada entre el principio de prioridad o relación y el de igualdad de trato a los acreedores o de comunidades pérdidas pasa de un estado inútilmente dogmático a otro de naturaleza pragmática y combinada que parte de considerar los elementos en común y las diferencias entre la ejecución civil singular y lo universal por un lado y la focalización de la tensión en el tipo de crédito o prestación cuya ejecución se solicita. Estas consideraciones que no pretenden polarizada entre principios, sino dar un tratamiento pragmático que parta de la consideración común de la ejecución y la diferenciación entre los diferentes tipos de crédito ejecutarse se vincula directamente con la forma de administrar la ejecución civil singular y la ejecución concursal en los supuestos disolventes.

\section{Modelos COMBINAdos Y EQUILIBRIO}

Los criterios de diferenciación tienen su razón de ser más allá de los contornos y pinceladas históricas que se dieron al respecto, en tratar de amoldar un sistema de ejecución singular trabajando con las siguientes preguntas: ¿Es razonable y útil distinguir entre créditos? ¿Cuál es la razón de ser práctica y utilidad de esta distinción? Y en segundo lugar de responderse afirmativamente, ¿̇cuál de las alternativas tiene mayor funcionalidad sistémica y práctica?

A la primera interrogante puede responderse acudiendo a los intereses en juego que fundamentan las distinciones y la reacción legislativa en los diferentes sistemas comparados. Ellos están íntimamente relacionados con la visión y co-

\footnotetext{
${ }^{73}$ Reifner, U. - Nieme, K. - Huls, N. - Springeneer, H., cit. (n. 68), pp. 251280.
} 
nexión entre la ejecución civil singular y universal. El elemento en común entre ambas es la concurrencia de acreedores por un lado y por el otro el interés de un deudor ejecutado en poder satisfacer los créditos de la mejor manera posible impidiendo su destrucción y "muerte" patrimonial que lo excluya del mercado laboral o comercial. ${ }^{74}$ De acuerdo a las soluciones o modelos que se adopten es posible decir que ellos se vinculan directamente con la distribución del riesgo de la insolvencia del ejecutado. El sistema de la prelación o de la prioridad trabaja fundamentalmente con la diligencia debida, libertad y autonomía privada o de la voluntad de los acreedores. Se reconoce que el que libremente y en primer lugar ejerce sus derechos acudiendo a la jurisdicción, obteniendo en su favor un embargo ejecutivo debiera ser preferido frente a otros acreedores posteriores en el tiempo, por ejercer sus derechos libremente decidido con posterioridad y postergación en el tiempo.

Por su lado el sistema de comunidad de pérdidas o de tratamiento igualitario de los acreedores pone el costo del riesgo de la insolvencia del deudor ejecutado directamente en los acreedores e indirectamente en la intervención del Estado, partiendo de un aparente postulado de igualdad de trato. El riesgo que el ejecutado o deudor ingrese en un estado de insolvencia, desechando por un lado la posibilidad de acudir a las normas sobre quiebra, o derecho concursal de la insolvencia por ser persona natural no comerciante impide que pueda sujetarse a las normas adecuadas, aunque vimos como se adecuaron sistemas como el francés regulando ello en materia de consumidores. De esta forma, salvo que el ejecutado tenga calidades especiales (como ser la de consumidor) en el cauce de la ejecución civil singular debiera ser soportada su insolvencia por partes iguales a prorrateo por sus acreedores ${ }^{75}$.

El tópico se torna bastante complejo por la polarización de las soluciones entre prelación versus comunidad de pérdidas y la decisión de política procesal-sustantiva de hacer depender una diferencia de trato a los acreedores en base a una mera diferencia temporal. Esta afirmación se complementa incluso con la solución intermedia existente en los modelos que adoptan la conformación de grupos de acreedores con distinta prelación de acuerdo al tiempo combinando la prioridad con la comunidad de pérdidas. Es que como se sostiene en esta propuesta, la solución no puede ser discutida sin la consideración de un sistema de ejecución integral en sus relaciones. La

${ }^{74}$ Sobre responsabilidad concursal (en la ejecución civil singular y universal) escalonada Berger, Christian, Haftungsrechtliche Verteilungsprinzipien an den Schnittstellen von Einzelzwangsvollstreckung und Insolvenz, en Zeitschrift für Zivilprozess, 121 (2008), p. 405; comp. AleXAnder, Eckhardt, Die Restschuldbefreiung (Köln, Heymmans , 2006), pp. 5-45.

${ }^{75}$ Adenas, Mads - Hess, Burkhard - Oberhammer, Paul, Enforcement Agency Practice in Europa (Londres, 2005), p. 24. 
separación y regulación muchas veces aislada, frecuentemente contradictorias en su fase práctica entre la ejecución civil singular y la ejecución universal impone la necesidad de coherencia. Es que justamente nos estamos refiriendo a un mismo tópico cuál es el de la ejecución, por ante un mismo fenómeno como es la concurrencia de acreedores y con un punto de inflexión que constituye el riesgo de la insolvencia del ejecutado que no puede ser ajeno a ningún sistema ejecutivo. De esta forma las respuestas a la segunda interrogante no pueden dejar de considerar el resguardo de todos los intereses en juego en la ejecución (civil singular y concursal - universal). Así no sólo los acreedores concurrentes, sino también el deudor y el Estado (con el costo social) titularizan intereses que van mucho más allá de la mera relación obligacional particular y cuyas consecuencias no pueden dejarse de considerar. No parece posible trabajar con el absurdo de un caso de ejecución, cuando en verdad el peligro de la insolvencia y la concurrencia de acreedores se dan dentro de un marco social y económico que imponen soluciones, que impidan el efecto dominó perjudicial en los intereses de una o de todas las partes intervinientes ${ }^{76}$.

En ninguno de estos dos sistemas procesales por su lado se contemplaba la posibilidad de la insolvencia de personas naturales que no sean comerciantes. Ello queda determinado a través de la regulación del embargo ejecutivo que no garantiza relación o prioridad de tal forma que debe acudir a la regulación del embargo ejecutivo posterior. Así, por ejemplo, el artículo 493 del Codice della Procedura Civile italiano conjuntamente con las disposiciones especiales de constitución de privilegios o preferencias legales con lo establecido en el propio artículo $2741^{77}$ del Codice Civile, que fundamenta el tratamiento con preferencia para la satisfacción del crédito de determinados acreedores, pero sin consideración al tiempo de inicio de la ejecución o de realización del embargo ejecutivo, sino en razón de la naturaleza del crédito. Sí debe dejarse claro que detrás de las opciones por uno u otro sistema no pueden ignorarse las externalidades de las distintas alternativas que puedan darse ${ }^{78}$.

${ }^{76} \mathrm{Cfr}$. con las directivas UNCITRAL sobre insolvencia, que se ven en: http://www. uncitral.org/pdf/english/texts/insolven/pre-judicial-perspective.pdf; para un estudio detallado con evidencia empírica Armour John - Cumming Douglas, The Legal Road to Replicating (Silicon Valley Centre for Business Research, University of Cambridge Working Paper No. 281, Cambridge, 2004), pp. 5-36.

${ }^{77}$ Una primera aproximación crítica a la ejecución civil contemporánea y a la necesidad de su reforma, entre otras, al régimen disperso de preferencias y a la carencia de prelación en el embargo, se ve en: Silvestri, Elissabeta, The Devil is in the Details. Enforcement and Enforceability. Tradition and Reform (Oxford, Intersentia 2010), pp. 147 y 207 ss..

${ }^{78} \mathrm{Ya}$ en los antecedentes históricos sobre la aplicación de los principios puede verse: ANDrioli, V., Il concorso di creditori nell esecuzione singolari (Roma, Soc. ed. Foro 
Quizá los modelos extremos y el intermedio puedan combinarse, y lo que simplemente se puede eliminar es la mayor intensidad de uno sobre los otros. La visión sobre la naturaleza y el rol de la ejecución civil singular y universal no pueden perder de vista la necesidad de incentivos que hagan previsible el respeto y cumplimiento adecuado de las obligaciones para la satisfacción de los créditos (visto desde el lado de los acreedores interesados), ello sin dejar de considerar la probabilidad de que el patrimonio del ejecutado pueda no llegar a ser suficientes en algún momento para la satisfacción de todas sus deudas $^{79}$. Así se torna imprescindible un sistema que permita la regulación preventiva antes del estado de insolvencia y que luego de este impida la exclusión patrimonial absoluta (muerte civil) del deudor ejecutado por un lado y que en la práctica pueda satisfacerse al menos porcentajes aceptables de los créditos en concurrencia ${ }^{80}$. Quizás sea aceptable el respeto de la autonomía privada, de los intereses y responsabilidades individuales de los acreedores intervinientes asumiendo el Estado una participación en la ejecución mediante una regulación especial de aquellas situaciones de probabilidad de acceso, cuando no de configuración del estado de insolvencia ${ }^{81}$.

Varios son los argumentos para sostener la necesidad de la prelación o prioridad temporal en la ejecución civil singular a partir del derecho sustantivo. En primer lugar no resulta aceptable la aplicación del tratamiento igualitario o de comunidad de pérdida desde el punto de vista de los derechos reales y las relaciones que surgen en este $\operatorname{marco}^{82}$. Así es posible distinguir

Italiano, 1937); más actual y crítico: LupoI, Michelle, Civil Enforcement in Italy: A Comparative Perspective, in Comparative Study of Civil Enforcement, en STÜRNER, R. Kawano, M. (directores), Comparative Studies on Enforcement and Provisional Meassures (Tübingen, Siebeck, 2011), pp. 92-98 ss.; comp. igualmente: Consolo, Claudio, Una buona "novella" al c.p.c.: la riforma del 2009 (con i suoi artt. 360 bis e 614 bis) va ben al di là della sola dimensione processuale, en Corriere Giuridico (2009), pp. 737 ss., espec. 740 ss.; Ricci, G.F. La riforma del processo civile. Legge 18 giugno 2009, n. 69. Disposizioni per lo sviluppo economico, la semplificazione, la competitività nonché in materia di processo civile (Torino, 2009), pp. 88 ss.

${ }^{79}$ Adenas, Mads - Hess, Burkhard - Oberhammer, Paul, Enforcement Agency Practice in Europe, (London, 2005), p. 24.

${ }^{80}$ Justamente analizando en el caso italiano la reformulación del caso del debito debitoris (embargo de créditos) sobre la reforma puede verse: Munhoz De Melho, Roberto, La nuova disciplina degli obblighi del terzo debitori ex art. 546 c.p.c, en Rivista di Diritto Processuale (2007), pp. 133 ss.

${ }^{81}$ Cfr. CApponi, Bruno, L'intervento dei creditori dopo le tre riforme della XIV Legislatura (dalla competitività alla Kessler, passando per gli interventi correttivi: Leggi 14 maggio 2005, n. 80, 28 dicembre 2005, n. 263, 24 febbraio 2006, n. 52, in Rivista dell'Esecuzione Forzata. (2006), pp. $22-28$ ss. espec. 24

${ }^{82}$ Cfr. Tarzia, Giusseppe, Il giusto processo di esecuzione, in Rivista di Diritto Processuale (2002), pp 329 ss. 
aquellos actos de disposición de carácter personal frente a aquellos de naturaleza real, siendo que los primeros tienen efecto relativo solamente entre las partes intervinientes, mientras que los segundos detentan un carácter absoluto. Como segunda premisa muy vinculada a la precedentemente descripta puede enunciarse como un límite a la autonomía de la voluntad en materia obligacional que no es permitido perjudicar a terceros aún por acuerdo de las partes. Ello porque como se dijo el efecto de los actos de disposición obligacional o de naturaleza personal es relativo. Así estaríamos pues en una contradicción técnica ya que justamente el ejercicio de la tutela ejecutiva singular por parte de un acreedor que obtiene un embargo ejecutivo primero en el tiempo en relación a otro u otros acreedores sucesivos, en realidad estaría recibiendo siempre un trato igualitario y finalmente frente a sucesivos y concurrentes acreedores podría verse perjudicado ante el riesgo del insolvencia del ejecutado.

El embargo ejecutivo puede o no implica la constitución de un derecho real de naturaleza accesoria o de garantía judicialmente constituido, en la tradición románica es más bien una medida de preparación para para el pago o realización. Pero también es cierto que sistemas como el anglosajón y el germano efectivamente se intensifica la garantía reconociendo la constitución de derechos reales de garantía en favor del ejecutante lo que precisamente fundamentan mucho más fácil la aplicación de la prioridad o prelación frente a otros acreedores concurrentes. Permite más fácilmente comprender que un derecho real solamente puede disponerse una sola vez, no pudiendo nadie transferir un derecho mejor del que titulariza, consecuentemente constituido determinado derecho real garantía por un tiempo no sería posible la constitución de un mismo derecho con el mismo rango y valor en forma sucesiva. De la misma forma que tampoco puede transferirse el dominio de un bien, sino sólo una vez entre determinado tradens con relación a determinado accipiens $^{83}$.

La prelación en la ejecución civil singular también parte de respetar la autonomía de la voluntad combinada con el efecto relativo de las disposiciones o de los actos de disposición personal. Esto de ninguna manera implica o podría implicar la afectación al principio de igualdad de armas, la apertura a la arbitrariedad o el desconocimiento de créditos posteriores. En el criterio temporal que sustenta el principio de prelación es razonablemente fundado por reconocer una primacía en el tiempo de aquel acreedor que a diferencia de otros decidió ejercer sus derechos ahora y no con posterioridad ${ }^{84}$. En el

\footnotetext{
${ }^{83}$ Satamm, cit. (n. 17), pp. 156 ss.

${ }^{84}$ Kengyel, Miklós - Harsági, Viktoria, "Generalbericht", en Los mismos, Grenzüberschreitende, cit. (n. 56), pp. 414 s.
} 
caso de la ejecución de transfrontera singular y especialmente universal asume un rol importante el sistema de distribución que se adopte para el respecto de los derechos de los acreedores, especialmente cuando se dan procesos colaterales al principal ${ }^{85}$.

Justamente viéndolo desde esta óptica podría argumentarse que este acreedor diligente que acudió, en el ejercicio de sus derechos de crédito, a la tutela ejecutiva por parte del Estado no debiera verse perjudicado en la posibilidad de asumir el riesgo de la insolvencia del ejecutado por el ejercicio del derecho de crédito por acreedores concurrentes con posterioridad. Así en virtud del efecto relativo de las relaciones personales como obligación tampoco podría sostenerse a un conjunto incierto de acreedores concurrentes que ejercieron en diferente tiempo sus derechos: ¿por qué debiera soportar en su conjunto el riesgo de la insolvencia del ejecutado por titularizar en realidad un crédito que debiera considerarse como parcial debido a que la agresión ejecutiva del Estado no recae sino sobre parte del patrimonio del ejecutado? Así el pretendido trato igualitario termina tratando desigual-

${ }^{85}$ Kengyel Miklós, Vorläufige Pfändung von Bankkonten, en Kengyel M. - HaRSÁGI V. (directores), Grenzüberschreitende, cit. (n. 56), pp. 366 s.; BERGLUnd, Mikael, Cross-Border Enforcement of Claims in the EU (The Hague, Kluwet Law International, 2009), pp. 216 s. Aun cuando difieran los Derechos nacionales, existen medidas para asegurar la prelación temporal, como el embargo de sumas de dinero o de cuenta corriente que se ingresan a nombre del juzgado o del oficial de ejecución competente. Así, por ejemplo, en "HIH Casualty and General Insurance Ltd." [2005] England, Wales, Hight Court, 2125; First appeal [2006] England, Wales, Court of Appeal Civil, 732. El grupo de $\mathrm{HIH}$ era un conjunto de grandes empresas que participaban en el giro de seguro y reaseguro en Australia, Inglaterra y los Estados Unidos, entre otros países. Hasta su colapso en marzo de 2001, el grupo de HIH fue el segundo mayor de seguros en Australia. El caso se refiere a cuatro miembros del grupo, cada uno involucrado en mayor o menor medida en los seguros y reaseguros en el Reino Unido. Aunque la mayoría de los activos de la empresas en Australia tenía además importantes activos en Inglaterra. Los procedimientos de insolvencia se iniciaron en Australia y en Inglaterra. Los representantes de la insolvencia inglesa solicitaron al tribunal instruya cómo distribuir los activos, debido a las diferentes normas de preferencia y trato a los acreedores existentes en Australia. Por su lado en Australia los tribunales actuaron conforme a sus leyes otorgando prelación a los acreedores de seguros sobre los de reaseguro, mientras que en Inglaterra se imponía la aplicación de la regla pari passu a todos los acreedores. Los representantes de la insolvencia en Australia solicitaron que los bienes embargados e incautados en Inglaterra queden a disposición de los tribunales australianos para su distribución según prelación de acuerdo a la calidad del crédito. En primera instancia, la Corte inglesa dictaminó que no podía remitir los activos inglés en Australia debido a la prioridad y el orden de distribución era diferente al que se aplica en Inglaterra. Por el perjuicio que se otorgaba a los acreedores postergados según la ley australiana, los tribunales ingleses rechazaron el pedido ya que se trataría en forma diferente a los acreedores del seguro en relación a aquellos del reaseguro. 
mente a los acreedores, porque pretende aplicar un trato igualitario a los acreedores como si la ejecución se realizara sobre la totalidad del patrimonio del ejecutado y no sobre una parte de este ${ }^{86}$. Así, el acreedor que en primer lugar obtuvo el resguardo de esa parte del patrimonio debiera ser satisfecho con la misma y no debe obligárselo en concurrencia con otros a someterse a la eventualidad de un crédito insatisfecho no sólo con una parte sino con la totalidad del patrimonio del ejecutado.

En los sistemas de tradición románica debe recordarse que la insolvencia es normalmente concebida como un estado patrimonial de un deudor con determinados atributos que le permitían acudir a la protección del derecho concursal o de quiebra, a saber su calidad de comerciante, empresario, quedando excluidas las personas físicas o naturales de dicha posibilidad ${ }^{87}$. Es que la insolvencia de las personas físicas o naturales debía quedar subsumida o incluida dentro de la ejecución civil singular e intentar ser resuelta justamente en este marco, soportando el riesgo de la insolvencia en todos los casos los acreedores. Es por ello que se explica la existencia de mecanismos como los denominados de tercería de pago que finalmente se terminan transformando en pequeños concursos o ejecuciones que suponen no sólo la pluralidad concurrente de acreedores en el estado de insolvencia del ejecutado. A esta tradición de raigambre principalmente francesa-italiana existe la alternativa de raíz anglosajona y germana de reconocer la prelación o prioridad en la ejecución civil singular y el trato igualitario en el supuesto de insolvencia, abriéndose la posibilidad de acudir a procedimientos preestablecidos de ejecución universal también a personas naturales con determinados procedimientos pensados para dichos supuestos ${ }^{88}$.

\section{CONCLUSIONES}

En la Europa contemporánea, tanto los sistemas románicos como los germánicos contienen, en mayor o menor medida, disposiciones que la declaración de insolvencia de las personas físicas o naturales con la posibilidad de un tratamiento especial, si bien con una regulación bastante disímil. Así, por ejemplo, en Francia ello se encuentra contemplado en materia de con-

${ }^{86}$ Tавво, Ch., Rethinking Preferences, en South Carolina Law Review, 43 (1992), p. 981.

${ }^{87}$ Mro $\beta$, Stefan, Zwangsvollstreckung im 21. Jahrbundert. Vom Forderungseinzug zum Forderungsmanagement? en Deutsche Gerichtsvollzieher Zeitung (2010), p. 21. Para el trasfondo y los antecedentes históricos, véase: Forster, Wolfgang, Vom Schandstein zum Konkursverfahren, en SMID, Stefan (Director), Aktuelle Probleme des geltenden deutschen Insolvenzrechts de (Berlin, De Gruyter, 2009), pp. 5 ss.

${ }^{88}$ Reifner, U. - Nieme, K. - Huls, N. - Springeneer, , cit. ( n. 68), pp. 251 ss. 
sumidores; o en Alemania y Austria (en su reformulación sobre la ejecución igualmente en $\mathrm{China}^{89}$ ), donde se considera la insolvencia de las personas naturales dentro de la normativa concursal, aún cuando se la designe como procedimiento concursal o de insolvencia de consumidores.

Un sistema que adopte modelos combinados con morigeraciones recíprocas parece ser la salida recomendable. Pero no debe olvidarse que en Francia, desde el año 1991, con la reforma de la ejecución forzada sobre créditos ordinarios, muchas fueron las morigeraciones al principio de contribución o de trato igualitario: ora porque para determinado tipo de embargos la atribución al ejecutante del bien se hace inmediatamente, excluyendo esa parte de la insolvencia y por otro lado impide la discusión de la concurrencia. Se debe agregar, además, que en la regulación desjudicializada para la distribución entre los acreedores valistas prima la actividad no contenciosa y, finalmente la incorporación de la figura del sobreendeudamiento brinda soluciones para un ámbito muy delicado y vulnerable en las relaciones, cual es el de los consumidores. Sí parece llegada la hora de comenzar a pensar en las bondades de la prelación, morigeraciones a la igualdad y simultáneamente la necesaria adopción de procesos para personas naturales previendo o actuando en la insolvencia en los países que aun quedaron amarrados a cánanones ya no actuales.

Hoy en día se frustra la regla de la par condicio creditorum, especialmente en la litigación de transfrontera. Solo hay que ver las dificultades nacionales que se generan en los Estados que aun la conservan sin morigeración alguna. Coinciden en muchos casos con la falta absoluta de regulación razonable de la insolvencia personal. En entorno legal con las variables económicas y financieras son de interés para la inversión, especialmente si de capitales de riesgo de trata. El riesgo de políticas públicas eventuales de salvataje son coyunturales y muchas veces tan volátiles como el propio capital de riesgo. La ingeniería de programas con inyección de fondos públicos no debiera sino darse dentro de un marco estructural previo y estable que impida el efecto negativo de capital de riesgo con sustento público ahora y sin él a corto o mediano plazo en desigualdad de competencia con aquellos que no se verían beneficiados por una política pública financiera de salvataje coyuntural. Aquí es donde adquiere relevancia la regulación de la insolvencia, como nuevo punto relevante a contemplar dentro de las variables. Si se analiza más detalladamente la insolvencia y el fenómeno de la concurrencia de acreedores es un riesgo relevante a contemplar ${ }^{90}$. Pero no refiero a la quiebra o concurso

\footnotetext{
${ }^{89}$ PISSLER, Knut, Das Oberste Volksgericht interpretiert das neue Zwangsvollstreckungsrecht in China, en Zeitschrift für chinesisches Recht, 17 (2010), pp. 28-36.

${ }^{90}$ Comp. con Sjostrand, Ekaterina, Cash Matters: Unsecured Creditor or Proprietary Interest? Analysis of the Recent Lehman Brothers' Case, en Corporate Rescue and Insolvency, 3 (2010) 1, p. 9
} 
de empresas, las que en mayor o menor medida cuentan con liquidez y limitaciones de responsabilidad que morigeran el impacto negativo frente a los acreedores y en su inserción. Por demás las alternativas de salvataje y manejo preventivo de una empresa siempre tiene cierto atractivo propio para el capital de riesgo.

Sí aludo más bien a la importancia de la regulación de la insolvencia personal, justamente por ser el crédito y el aporte "personal" o "familiar" la base del emprendimiento. El reinicio luego de la insolvencia implica un costo de oportunidad que normalmente está contemplado en las leyes sobre regulación de la insolvencia personal mediante el "Freesh start". Una regulación eficiente de la tutela del crédito debe a su vez contemplar la regulación de la insolvencia no solo empresarial, sino también personal con menos elementos punitivos que puedan rehabilitar al deudor y no conviertan ese estado temporal en un estatus permanente ${ }^{91}$.

Aunque a primera vista pueda intuirse una contradicción entre "insolvencia" y "financiamiento de capital en riesgo". A primera vista, la regulación de la insolvencia personal tendría poco impacto ya que el capital de riesgo está donde se aplica ya el sistema de quiebra de empresas o corporativo. No obstante esta primera asunción no considera que justamente la regulación de la insolvencia personal actúa antes como disuasión de forma de estar en condiciones de poder acceder al capital de riesgo, pero también incide una vez que el emprendedor fracasó y se está rehabilitando por medio de los procedimientos de insolvencia previstos, ya que no podrá ingresar nuevamente al mercado sin ahora, una condición calificada que lo libere de la insolvencia ${ }^{92}$. Es decir, habrá mecanismos de certeza que consideren como nuevamente sustentable a ese emprendedor otrora insolvente. Antes y después hay incentivos para estar o reasumir una condición de postulación para sentar las bases de recepción de capital de riesgo, partiendo de las personas que luego podrían conformar la corporación. En definitiva hay un costo en los sistemas que no cuentan con la posibilidad de la insolvencia de personas naturales en tanto podrían faltar incentivos significativos para que los individuos puedan participar en actividad empresarial, con mayor razón si es de alto riesgo ${ }^{93}$. En términos generales, los procedimientos de insolvencia personal suelen dar lugar a una cesión de la propiedad del deudor de la mayoría de sus bienes en favor de

${ }^{91}$ Ayотте, Kenneth, Bankruptcy and Entrepreneurship: The Value of a Fresh Start, en Journal of Law, Economics, and Organization, 23 (2007), pp. 161 - 185.

${ }^{92}$ Georgokopoulos, Nicholas, Bankruptcy Law for Productivity, en Wake Forest Law Review, 37 (2002), pp. 51-95.

${ }^{93}$ Lee, Seung-Hyun - Yamakawa, Yasuhiro - Peng, Mike W. - Barney Jay B., How do Bankruptcy Laws Affect Entrepreneurship Development around the World? en Journal of Business Venturing , 26 (2011), pp. 505-520. 
un administrador que dirige la liquidación, pagos a los acreedores, planes de pago y destino de los nuevos ingresos que experimente el patrimonio del deudor. En general toda actividad que implique administrar y resguardar el patrimonio afectado para que pueda pagar según como se haya planificado. Especial importancia tendrá que, en un momento dado el deudor pueda acceder a la posibilidad de un nuevo inicio que lo habilita a una reinserción total para el emprendimiento. Cada sistema de regulación de la insolvencia personal es más o menos estricto en las condiciones que impone, pero lo cierto es que impiden que el deudor se convierta en un "muerto civil". La confianza en que el emprendedor que fracasó podría volver a iniciarse genera un efecto positivo frente a la realidad de fracaso con sanción eterna que impida rehabilitarse financieramente ${ }^{94}$.

No da lo mismo una sistema puro de isonomía, prioridad o de agrupamiento de acreedores sin morigeraciones adecuadas que no solo se manifiestan en una reformulación de las prelaciones, sino también en el adecuado manejo del riesgo de la insolvencia corporativa y especialmente personal.

\section{BIBLIOGRAFÍA}

Abrams - Wagner, Priority Rules An Empirical Exploration of First-to-Invent Véase: sus First-to-File, en Public Law and Legal Theory (University of Pennsylvania Law School, Research Paper N 11-37, Draft 9.6.2011) [visible en> http://ssrn.com/ abstract $=1921488$, visitado el 20 de octubre de 2011].

Adenas, Mads - Hess, Burkhard - Oberhammer, Paul, Enforcement Agency Practice in Europa (Londres, 2005).

Alexander, Eckhardt Die Restschuldbefreiung (Köln, Heymmans, 2006).

Amonn Kurt - Walther Fridolin, Grundriss des Schuldbetreibungs-und Konkursrechts ( $7^{\text {a }}$ edición, Berna 2010).

Andrews, Neil - Turner, Robert, en van Rhee, Remco - Uzelac, Alan, Enforcement and Enforceability-Tradition and Reform (Oxford, Intersentia, 2010).

ANDrioli, V., Il concorso di creditori nell esecuzione singolari (Roma, Soc. ed. Foro Italiano, 1937).

Armour John - Cumming Douglas, The Legal Road to Replicating (Silicon Valley Centre for Business Research, University of Cambridge Working Paper n. 281, Cambridge, 2004).

Ayотте, Kenneth, Bankruptcy and Entrepreneurship: The Value of a Fresh Start, en Journal of Law, Economics and Organization, 23 (2007).

Ayotte Kenneth - SkeEL, David, Bankruptcy or Bailouts? en Journal of Corporate Law, 35 (2010).

Baird, Douglas - Gertner, Robert - Picker, Randal, Game Theory and the Law (Massachuset, Harvard U. Press, 1998).

${ }^{94}$ Cumming, cit. (n. 31). 
BAUR, Fritz, Losprincipios deprioridad e igualdad en la jurisdicción voluntaria, en Boletín Mexicano de Derecho Comparado, 22-23 (1975).

BeCker, Colin, First in Time, First in Right (Berlin, Duncker \& Humblot, 2000).

BÉGUERI, Mark, Le dispositif de traitement des situations de surendettement des particuliers: les principaux effets de la loi Lagarde, en Bulletin de la Banque de France, 182 ( $4^{\circ}$ trimestre de 2010).

Berger, Christian, Haftungsrechtliche Verteilungsprinzipien an den Schnittstellen von Einzelzwangsvollstreckung und Insolvenz, en Zeitschrift für Zivilprozess, 121 (2008).

Berglund, Mikael, Cross-Border Enforcement of Claims in the EU (The Hague, Kluwet Law International, 2009).

Bone, Robert, Procedure, Participation and Rights, en Boston, Boston University Law Review, 90 (2010).

Bourin, Vincent - Vigneau, Guillaume, Droit du surendettement des particuliers (Paris, Litec, 2007).

BRISSAUD, Jacques, Le creancier "premier saisissan” dans l ancien Droit français (Paris, Presses Universitaires de France, 1972).

CAPPONI, Bruno, L'intervento dei creditori dopo le tre riforme della XIV Legislatura (dalla competitività alla Kessler, passando per gli interventi correttivi: Leggi 14 maggio 2005, n. 80, 28 dicembre 2005, n. 263, 24 febbraio 2006, n. 52, in Rivista dell'Esecuzione Forzata (2006).

Cavalier, Georges, The French Bankruptcy, en Stürner, R. -Kawano, M. (directores), Comparative Studies on Enforcement and Provisional Meassures (Tübingen, Siebeck, 2011).

Chardon, Mathieu, Enforcement in France, in van Rhee, Remco - Uzelac, Alan, Enforcement and Enforceability. Tradition and Reform (Oxford, Intersentia, 2010).

CoING, Helmut, Europäisches Rechtsgeschichte (München, Beck, 1985).

Cole, Daniel - Grossman, Peter, Institutions Matter! Why the Herder Problem Is not a Prisioner's Dilemma, en Theory \& Decision, 69 (2010) 2.

Cole, Daniel - Grossman, Peter, Principles of Law \& Economics (2a edición, New York, Wolster Kluwer, 2011).

Consolo, Claudio, Una buona "novella" al c.p.c.: la riforma del 2009 (con i suoi artt. 360 bis e 614 bis) va ben al di là della sola dimensione processuale, en Corriere Giuridico (2009).

Cortés Domínguez, Valentín, La naturaleza jurídica de la declaración judicial de concurso, en Olivencia, M. - Jiménez de Parga, R. - Fernández-Novoa, C. - (directores) Derecho procesal concursal (Barcelona, Marcial Pons, 2008).

Cumming Douglas, Measuring the effect of bankruptcy laws on entrepreneurship across countries, Journal of Entrepreneurial Finance, en prensa (2011), (visitado la última vez el 10 de noviembre de 2011 http://ssrn.com/abstract=1970042)

De Castro jr., Francisco, Da insolvencia civil no ponto de vista do Direito patrio, da historia e da legislação comparada (São Paulo, Laemmert, 1903).

DE LeVal, Georges, Seizure and Overindebtedness in the European Union (La Haya 1997).

Delmotte Philippe, L'égalité des créanciers dans les procédures collectives, visible en : www.courdecassation.fr [visitado el 11 de diciembre de 2010].

Díez Soto, Carlos Manuel, Concurrencia y prelación de créditos: teoría general (Madrid, 2006). 
Donnier, Marc - Donnier, Jean-Baptiste, Voies d'exécution et procedure de distribution (Paris, Litec, 2009).

Engel, Kathleen - Mccoy, Patricia, The Subprime Virus (Oxford, Oxford U. Press, 2011).

FISCHER, Nikolaj, Vollstreckungszugriff als Grundrechtseingriff(Tübingen 2006).

Finch, Vanessa., Is Pari Passu Passe? en Insolvency Lawyer (2000) 5 (octubre).

Finch, Vanessa, The Recasting of Insolvency Law, The Modern Law Review. (2005), $68(5) .$.

Forster, Wolfgang, Konkurs als Véase: fahren: Francisco Salgado de Somoza in der Geschichte des Insolvenzrechts (Köln - Weimar, Böhlau 2009).

ForSTER, Wolfgang, Vom Schandstein zum Konkursverfahren, en SMID, Stefan (duirector), Aktuelle Probleme des geltenden deutschen Insolvenzrechts de (Berlin, De Gruyter, 2009).

Fragistas, Charalambos, Das Präventionsprinzip in der Zwangsvollstreckung (Mannheim, 1931).

Fricero, Natalie, Procédures civiles d'exécution: Voies d'éxecution, procédures de distribution (Paris, 2010).

Fuchs-Wissemann, Hanns, Priorität und Recht, en Deutsche Richter Zeitung (1982).

GARREAU Christophe, La saisie-attribution, la procédure collective et la date de naissance des créances contractuelles, en Revue Trimmestrale de Droit Commercial, 3 (2004).

Gaul, Hans F., Rechtsverwirklichung durch Zwangsvollstreckung, en Zeitschrift für Zivilprozess, 112 (1999).

Georgokopoulos, Nicholas, Bankruptcy Law for Productivity, en Wake Forest Law Review, 37 (2002), pp. 51-95.

GIRARD Pierre-André - Prohaszka Jean-Pierre, La détermination des droits des créanciers saisissants en cas de concours, en La Semaine Juridique Notariale et immobilière, 12 (marzo de 2003).

Hess, Burkhard, Europäische Zwangsvollstreckungsrecht: Herausforderung und rechtpolitische Perspektiven, en Deutsche Gerichtsvollzieher Zeitung (2010).

JACKSON, Thomas SkeEl, David, Bankruptcy, Banks, and Nonbank Financial Institutions (Wharton Fin. Inst. Cent. Workshop, Feb. 8, 2010).

KAHIL, Omran, L'égalité entre les créanciers Dans le cadre de la saisie attribution, Tesis doctoral Universidad Lille 2 (Francia, 2011)

Kasser, Max, Das Römisches Privatrecht (München, Beck, 1971).

KaWANO, Masanori, Civil Enforcement as a Fundamental of Effective Justice-Introductory Remarks on Comparative Study of Civil Enforcement, en STÜRNER, R - KAWANO, M. (directores), Comparative Studies on Enforcement and Provisional Meassures (Tübingen, Siebeck, 2011).

Kengyel, Miklós - Harsági, Viktoria, Grenzüberschreitende Vollstreckung in der Europäischen Union (München, Sellier, 2011).

Kerameus, Konstantinos, Enforcement in the International Context, en Recueil des Cours, 264 (1997).

Kerameus, Konstatinos, Actual Problem of Enforcement Law in the European Union, en Homenaje a Peter Schlosser zum 70. Geburstag. Grenzüberschreitungen (Tübingen, Mohr-Siebeck, 2005).

Kerameus, Konstatinos, Enforcement Proceedings, International Encyclopedia of Com- 
parative Law, XVI: Civil Procedure, en CAPpeletti, Mauro (editor) (Tübingen, 2002).

Klamaris, Nikolaos, Zum Stand des griechischen Zwangsvollstreckungsrechts: eine zusammenfassende Skizze, en Zeitschrift für Zivilprozess, 121 (2008).

Koenne, Phil, The Cult of Legislation (New York, Publishing Packagers Corp., 1991).

Konecny, Andreas, Konkurs ist ein Konkurs ist ein Konkurs, en Festschrift Rechberger (Viena, Spring, 2005).

Krings, Ernerst, Seizure and Overindebtedness in the European Union, en De LeVAL, Georges (director), Seizure and Overindebtedness (véase).

Kroener, William, Expanding FDIC-Style Resolution Authority, en Ending Government Bailouts As We Know Them (2010).

Lasarte, Carlos - López Peláez, Patricia - YÁñez Viver, Fátima, La reforma de la prelación de créditos (Madrid, Cuadernos de Derecho Registral, 2007).

Lebre De Freitas, José, Seizure and Overindebtedness in the European Union, en DE Leval, G., (director), Seizure and Overindebtedness (véase).

Lee, Seung-Hyun - Yamakawa, Yasuhiro - Peng, Mike W. - Barney Jay B., How do Bankruptcy Laws Affect Entrepreneurship Development around the World? en Journal of Business Venturing , 26 (2011).

LEFORT, Christopher, Saisie-attribution, en Repertoire de Procedure Civile (Paris, Dalloz, enero 2007).

LEPA, Brita, Insolvenzordnung und Verfassungsrecht (Berlin, Ducker \& Humblodt, 2002).

Levinthal, Louis Edward, The Early History of Bankruptcy Law (Pennsylvania, 1918).

Lienhard Alain, Saisie-attribution de créances à exécution successive: leffet attributif plus fort que l'égalite des créanciers, en Observations sous Cassation Chambre Mixte (22 noviembre 2002).

López Peláez, Patricia,Los créditos preferentes en el Derecho español (Madrid, Trivium, 2001).

LupoI, Michelle, Civil Enforcement in Italy: A Comparative Perspective, in Comparative Study of Civil Enforcement, en STÜrner, R. - Kawano, M. (directores), Comparative Studies on Enforcement and Provisional Meassures (Tübingen, Siebeck, 2011).

Maniotis, Dimitris, en Stürner, R. -Kawano, M. (directores), Comparative Studies on Enforcement and Provisional Meassures (Tübingen, Siebeck, 2011).

McCullough, When First in Time is not First in Right, en Loyola University Chicago Law Journal, 25 (1994).

Meier, Isaak - Zweifel, Peter - Zaborowski, Christoph - Jent-sørensen, Ingrid, Aufder Suche nach dem optimalen Existenzminimum, eine rechtliche und ökonomische Analyse der Einzelzwangsvollstreckung gegen Privatpersonen in der Schweiz mit Erarbeitung von Reformvorschlägen, en Blätter für Schuldbetreibung und Konkurs (1998).

MeIer Isaak - Perrier Camille, Sanierung und Entschuldung von Privatpersonen nach französischem Recht. Ein Vorbild für das schweizerische Recht? en Zeitschrift für Schweiserisches Recht (2006) 1.

MeIER, Isaak, Die dogmatische Situation des Vollstreckungsrechts aus der Sicht des schweizerischen Rechts, en Zeitschrift für Zivilprozess, 121 (2008) [versión actualizada en 
Aktuelle Probleme der Zwangsvollstreckung aus Sicht des schweizerischen und türkischen Rechts, en Blätter für Schuldbetreibung und Konkurs (2010)].

Meier Isaak - Zweifel Pete - Zaborowski Christoph - Jent-sørensen Ingrid, Auf der Suche nach dem optimalen Existenzminimum, eine rechtliche und ökonomische Analyse der Einzelzwangsvollstreckung gegen Privatpersonen in der Schweiz mit Erarbeitung von Reformvorschlägen, en Blätter für Schuldbetreibung und Konkurs (1998).

Miniato, Lionel, Voies d'exécution et procédures de distribution (Paris, 2009).

Mokal, Rizwaan Jameel, Priority as Pathology: the pari passu Myth, en Cambridge Law Journal, 60 (2001).

Mroß, Stefan, Zwangsvollstreckung im 21. Jahrhundert. Vom Forderungseinzug zum Forderungsmanagement? en Deutsche Gerichtsvollzieher Zeitung (2010),

Munhoz De Melho, Roberto, La nuova disciplina degli obblighi del terzo debitori ex art. 546 c.p.c, en Rivista di Diritto Processuale (2007).

Neuner, Jörg, Der Prioritätsgrundsatz im Privatsrecht, en Archiv für die Civilistische Praxis, 203 (2003).

Olivencia Ruiz, Manuel, La terminología jurídica de la reforma concursal (Madrid, Iustel, 2006).

Orfanidis, Georgios, Die Konkurrens von Gläubigern im griechischen Zwangsvollstreckungsrecht. Grenzüberschreitungen: Beiträge zum internationalen Verfahrensrecht und zur Schiedsgerichtsbarkeit, en Festschrift für Peter Schlosser zum 70 Geburtstag (Tübingen, Mohr Siebeck, 2005).

PajIC, Natasa, Enforcement and Execution in the USA, en van Rhee, Remco - Uzelac, Alan, Enforcement and Enforceability. Tradition and Reform (Oxford, Intersentia, 2010).

Perrot, Roger, -Thery, Philippe, Saisie attribution: la situation du tiers saisi (arrêts 5.7. 2000) (Paris, Dalloz, 2001).

PISSLER, Knut, Das Oberste Volksgericht interpretiert das neue Zwangsvollstreckungsrecht in China, en Zeitschrift für chinesisches Recht, 17 (2010).

Pluta, Maximilian, Insolvenzaufrechnung und der Grundsatz der "par conditio creditorum" (Bielefeld, Gieseking, 2009).

Pond, K., Creditor Strategy in Individual Insolvency, en Managerial Finance, 28 (2002) 6.

Rechberger, Walter - Oberhammer, Paul, Exekutionsrecht (Viena, Facultas, 2010).

Reifner, Udo - Nieme, Kiesiläine - Huls, Nik - Springeneer, Helga, Overindebtedness in European Consumer Law: Priciples from 15 European States (London, POd, 2010).

RICcI, G.F. La riforma del processo civile. Legge 18 giugno 2009, n. 69. Disposizioni per lo sviluppo economico, la semplificazione, la competitività nonché in materia di processo civile (Torino, 2009).

Rosenberg, Leo - Gaul, Hans - Schilken, Eberhard - Becker-Eberhard, Ekkehard - PanAjOTta Lakkis, Zwangsvollstreckungsrecht (München, 2010).

SAlgado de Somoza, Francisco, Labyrinthus creditorum concurrentium ad litem per debitorem communen inter ilios causata (Fratrum de Tournes, 1757).

SCHLOSSER, Peter, Volksstreckungsrechtliches Prioritätsprinzip und verfassungsrechtliche Gleiheitssatz, en Zeitschrift für Zivilprozessrecht, 97 (1984).

Schpani, Sandro, "Principia Iuris. Principium potissima pars". Principios generales 
del derecho (Apuntes para una investigación), en Roma e America. Diritto Romano Comune, 3 (1997).

Shavell, Steven, Foundation of Economic Analysis of Law (Cambridge, Harvard U. P., 2004).

Siebert, Peter, Das Prioritätsprinzip in der Einzelzwangsvollstreckung (Diss. Göttingen 1988).

Silvestri, Elissabeta, The Devil is in the Details. Enforcement and Enforceability. Tradition and Reform (Oxford, Intersentia 2010).

Sjostrand, Ekaterina, Cash Matters: Unsecured Creditor or Proprietary Interest? Analysis of the Recent Lehman Brothers' Case, en Corporate Rescue and Insolvency, 3 (2010) 1, p. 9

SPÜHLer Kar - Gehri Myriam, Schuldbetreibungs- und Konkursrecht (Züric Basel - Genf, 2008).

STADLER, Astrid, Gestaltungsfreiheit und Verkehrsschutz durch Abstraktion (Tübingen, Siebeck, 1996).

Stamm, Jürgen, Die Prinzipien und Grundstrukturen des Zwangsvollstreckungsrechts (Tübingen 2007).

STÜRNER, Rolf, Prinzipien der Einzelvollstreckung, en Zeitschrift für Zivilprozess, 99 (1986).

Тавво, Ch., Rethinking Preferences, en South Carolina Law Review, 43 (1992).

Tarzia, Giusseppe, Il giusto processo di esecuzione, in Rivista di Diritto Processuale (2002).

TARZIA, Giusseppe, La distributions des derniers dans lexécution forcée en Europe, en Revue Internationale de Droit Comparé, 51 (1999) 2.

Terré, François, Droit de la fallite ou fallite du droit, en Revue de Jurisprudence Commercial (1999).

ThÉRY, Phlippe, Seizure and Overindebtedness in the European Union, en DE LEVAL, G. (director), Seizure and Overindebtedness (véase).

Vollmershausen, Christiane, Vom Konkursprozess zum Marktbereinigungsverfabren (Münster, LIT, 2007).

WaCKe, Andreas, Wer zuerst kommt, mabl zuerst, en Juristen Ausbildung (1981).

WeIsL, Ernst, Deutsche Pfandrecht bis zur Reception des Romischen Rechtes (Viena, 1881).

WeLbers, Hartwig, Vollstreckungsrechtliches Prioritätsprinzip und verfassungsrechtlicher Gleichheitssatz (Diss., Bonn 1991).

White, Michell, Bankruptcy Law, en Polinsky, Mitchell - Shavell, Steven (editores), Handbook on Law and Economics (Amsterdam, 2007).

Yessiou-Faltsi, Pelaya - Pipsou, Linda, Seizure and Overindebtedness in the European Union, en DE Leval, G. (director), Seizure and Overindebtedness (véase). 
